Article

\title{
Implementing Blockchain Technology in Irrigation Systems That Integrate Photovoltaic Energy Generation Systems
}

\author{
Florentina Magda Enescu $1, *$, Nicu Bizon ${ }^{1,2,3, *(\mathbb{D}}$, Adrian Onu ${ }^{4}$, Maria Simona Răboacă ${ }^{2}(\mathbb{D}$, \\ Phatiphat Thounthong ${ }^{5}\left(\mathbb{D}\right.$, Alin Gheorghita Mazare ${ }^{1}$ and Gheorghe Șerban ${ }^{1}(\mathbb{D}$ \\ 1 Faculty of Electronics, Communications and Computers, University of Pitesti, 110040 Piteşti, Romania; \\ alin.mazare@upit.ro (A.G.M.); gheorghe.serban@upit.ro (G.S.) \\ 2 National Research and Development Institute for Cryogenic and Isotopic Technologies-ICSI Rm. Valcea, \\ 240050 Ramnicu Valcea, Romania; simona.raboaca@icsi.ro \\ 3 Doctoral School, Polytehnic University of Bucharest, 060042 Bucharest, Romania \\ 4 R\&D Department, ASSIST Software, 720043 Suceava, Romania; adrian.onu@assist.ro \\ 5 Renewable Energy Research Centre (RERC), King Mongkut's University of Technology North Bangkok, \\ Bangkok 10800, Thailand; phatiphat.t@fte.kmutnb.ac.th \\ * Correspondence: florentina.enescu@upit.ro (F.M.E.); nicu.bizon@upit.ro (N.B.)
}

Received: 29 December 2019; Accepted: 16 February 2020; Published: 18 February 2020

\begin{abstract}
Traditionally, the energy industry has been slow in adopting new disruptive technologies and the transition to a new energy market will require a new digital transformation plan, involving all parties from the energy market. Although it now seems to be an impossible and hard-to-accept scenario, especially by the big players in the industry, the pilot projects so far demonstrate that blockchain can play a major role in the future energy market, even if the technology is still in the first stages of the adoption life cycle. This article attempts to describe a solution to provide alternative irrigation systems for small farmers. The solution involves creating associations of small farmers that will use green energy from photovoltaic panels for the irrigation of agricultural lands. The efficiency of the proposed system can be monitored not only through digital hardware connected to photovoltaic panels and water pumps, but also by using the new blockchain technology that stimulates innovation and growth in the energy and a high level of automation though smart contracts. To accelerate the transition to the green energy economy, a SolarCoin version similar to the Bitcoin cryptocurrency has also been proposed, which is a utility token that creates new possibilities for energy and water trading.
\end{abstract}

Keywords: irrigation system; photovoltaic water pumping systems (PWPS); floating photovoltaic panels; SCADA; blockchain; SolarCoin

\section{Introduction}

It is expected that in about 12 years, more than half of the electricity produced in the European Union will come from renewable energy sources, and the decarbonization of electricity is expected to be achieved by 2050 [1]. Under these conditions, the entire energy industry will have to go through a massive transformation, which will affect everyone in the value chain from the production, consumption, distributors, and networks [2-5].

The use of solar energy in various applications has grown over the past few years, and the irrigation sector is one of its most appropriate uses [6-8]. Many agricultural producers are attracted to this solution as it helps to maximize their profits by reducing the costs of electricity or fuel [9-11]. In addition, during the cold season after the irrigation interruption, electricity obtained from the 
photovoltaic panels can still be used at high capacity to supplement the energy required to run the farm $[4,12,13]$.

Photovoltaic systems are ideal in isolated areas that do not have access to the national energy system. Below, the most important advantages of applying the photovoltaic systems in agriculture have been listed [14-16]:

If the annual electricity consumption is known, then the photovoltaic system is easy to design because the network-connected systems have a small number of components and do not require too much space.

Research has confirmed that plants can also work with unfiltered water or chemical fertilizers dissolved in water.

Photovoltaic technology is getting cheaper. It does not rely on intense sunlight. The technology is simple enough to be easily implemented.

Irrigation is mandatory in obtaining profits from agriculture.

When pumping water, farmers need energy, but energy distributors sell it at too high a price for farmers' incomes and they are not interested in using irrigation channels.

Existing irrigation channels have deteriorated over time due to abandonment, which can be due to bad intentions.

This can be argued by the collection of images from a farm (see Figure 1) that resorted to these possibilities of realizing the irrigation of agricultural lands by using renewable energy, obtained with the help of PV (photovoltaic) panels [17].

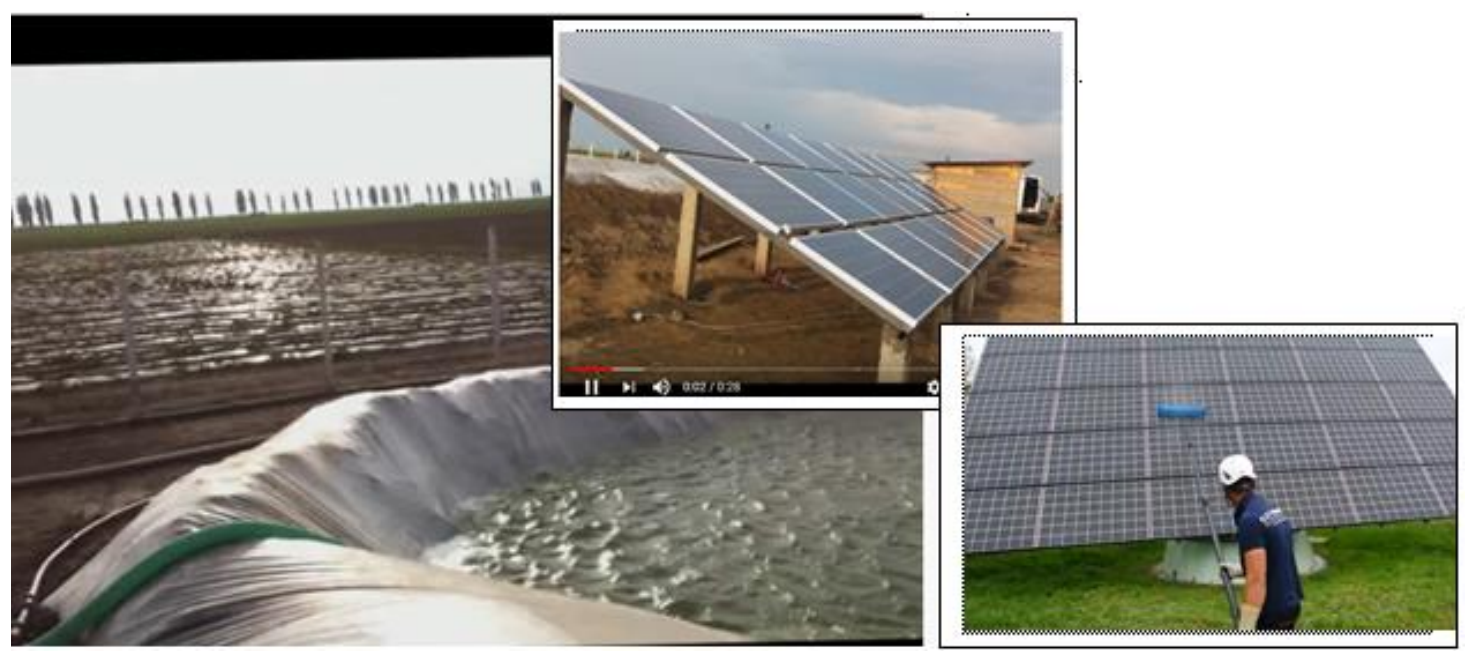

Figure 1. Photovoltaic panels used for irrigation.

In the study carried out, the surplus of energy obtained in the months with a greater number of hours with brightness will not be stored in batteries but will be traded by cooperatives from which the farm is part to another cooperative or farm to the national system.

Regarding the maintenance of the panels (cleaning), high costs are not necessary, and in the case of a large number of panels, there are automatic systems for cleaning by miniroboting [18]. The possible lack of the national energy system in the area where the farm (cooperative) is located must also be considered [19].

Considering the adoption level of solar energy, it might be recommended for the small producers to make use of any additional income source, such as SolarCoin. Being based on blockchain technology [20-31], SolarCoin is global and decentralized, similar in many ways to cryptocurrency such as Bitcoin, but more efficient and environmentally friendly [32-34]. SolarCoin stands out because, 
unlike other types of cryptocurrency, it ensures contribution to an economically and environmentally beneficial activity by vertically produced solar energy [35-37].

The study [38] has showed that despite the barriers to using blockchain technology, these technologies contribute to the Sustainability Development Goals by producing a series of changes and practices in various fields. In [39], the blockchain technology has been taken into consideration for an irrigation system.

We are proposing a software solution based on Ethereum blockchain and Distributed Ledger technology that aims to reduce the costs for farmers related to irrigation systems. A somewhat similar blockchain-based software platform was built and launched in Australia-Power Ledger (https://www.powerledger.io/) is a platform where businesses and consumers can trade energy peer-to-peer. The platform primarily caters to clean energy, such as wind and solar energy, that can be produced by individuals and businesses and then shared.

The main objectives and the novelty of this study are as follows:

(1) The proposal of a new solution to create individual microgrids for the small producer associations in a way that is most advantageous for both the producers and consumers, by assuring a reliable and transparent energy tracking solution achieved through decentralization of data and use of blockchain technologies;

(2) Presenting the possibilities of acquiring energy through blockchain utility tokens and SolarCoin technologies and comparing the obtained results in order to choose the solution that can bring the most benefits compared to the size of association;

(3) Proposing a way of placing the photovoltaic park so that agricultural lands cannot be affected, and the water stored in the channel is kept at a higher quality.

(4) Analyzing the current stage of the irrigation system used as a case study to integrate photovoltaic energy system and proposing solutions to solve the afore identified issues.

Also, this study presents the energy production of a photovoltaic system that may be coupled with the proposed Photovoltaic Water Pumping System (PWPS) when more energy for irrigation is necessary.

Thus, the structure of the paper is as follows: Different possibilities of energy transaction's first advanced methods and Blockchain SolarCoin variant are presented in Section 2. The model of the energy consumption flow within a farmers' association is presented in Section 3. The experimental study for an irrigation system based on renewable energy is presented in Section 4. The design of the photovoltaic energy system needed to supply the water pumps and the SCADA system for the association, and the analysis of the energy generated by the photovoltaic system during a year are also discussed based on the main results presented in an appendix. The proposed approach to reduce costs for the system under study is presented and discussed in Section 5. The last section concludes the paper.

\section{Current State of Irrigation Systems}

Regarding the water balance in Europe, $44 \%$ of captured water is used for energy production, $24 \%$ for agriculture, $21 \%$ for water supply to the population, and $11 \%$ for industry [1]. However, this distribution varies depending on location; in southern Europe, for example, agriculture accounts for $60 \%$ of the total water captured, with the percentage even reaching $80 \%$ in certain areas [1].

It is supposed that with the change of rainfall regimes, some parts of Europe will have more freshwater resources in the future and other parts will not be able to cover the overall need.

Crop irrigation is an area in which innovative practices and new policies can significantly facilitate the efficient use of water. In southern European countries such as Greece, Italy, Portugal, Cyprus, Spain, and southern France, arid or semi-arid conditions require the use of irrigation. In these areas, almost $80 \%$ of the water used in agriculture is currently used for irrigation [1-3]. A methodology that allows an optimal estimation of water quantity and energy used in an irrigation system in Spain has 
been presented in [4]. Another example, which has been verified in the long run by such a system, was developed by Daud and Mahmoud in Jordan [5]. The water is extracted from a well and the available average solar radiation is $5.5 \mathrm{kWh} / \mathrm{m}^{3} /$ day. The tests proved the safety of the system with a general efficiency of more than $3 \%$. This result was compared with similar studies that reported a high efficiency for photovoltaic solar water pumping systems [6-8].

In Romania, the situation is entirely different. The agricultural lands are large, there are many freshwater sources, and before 1989, Romania had an irrigation network spread over an area of 3.2 million hectares, which was almost entirely destroyed with the installations being stolen or left to waste. Most functional irrigation systems from 1989 have been dismantled and some have not even been built [3].

In May 2009, irrigation facilities for 563,000 hectares of agricultural land were in operation, of which 553,000 hectares (or 99\%) were contracted by irrigation water user organizations [3].

In the irrigation field, Romania has a deficit of 2.6 million unrecorded hectares. In 2009 in Romania, 2.6 million hectares of land were unrecorded when it comes to irrigation statistics (today the area is even larger). According to these statistics, 300,000 hectares of land is irrigated, but in fact, there are only 100,000 hectares. Other sources indicate an irrigated area of 560,000 hectares [3].

For small farmers (usually with between 1 to 10 ha of land) located in areas with no electricity, it is appropriate and necessary to use funding opportunities for the purchase of mobile drip irrigation equipment (dripping or spraying) and for the insurance provision of electricity for the water pumps based on the photovoltaic panels [9-11].

Romania has one of the largest agricultural potentials in Europe, having a really high hydrological potential and a major advantage for organic farming (pollution of agricultural lands is still low compared to other EU countries).

Unfortunately, due to the destruction of the old irrigation system and the absence of a coherent governmental plan or other viable solution, a significant part of the agricultural area has been deserted.

To rehabilitate irrigation systems, high investments are needed, but besides that, there is the possibility for small farmers to not be able to afford purchasing water from rehabilitated irrigation systems, as the costs are high compared to the obtained incomes [17-19].

Although difficult to query for data in distributed databases, as stated in [39], they still provide fast processing. The biggest advantage of distributed ledger technology (DLT) is the ability to build trust in digital ecosystems [40].

Taking into consideration the security risks of a highly automated decentralized digital system for this kind of applications, the possible risks involved cannot be neglected. The Ethereum blockchain is one of the most used for deploying and running smart contracts, with lots of decentralized applications already in production [20-22]. As an open-source platform, it is already being code reviewed by the community, and thus it is one of the most secure platforms to run smart contracts on [23-25]. It is worth mentioning that all the software modules require core development principles, such as security in depth, unit testing, pre-and post-condition sanity checks, code consistency, and regular audits [26-28].

The performances of a photovoltaic system supervised by Supervisory Control and Data Acquisition (SCADA) system highlighted in [41,42] and the online surveillance on mobile applications as shown in [43] further accentuate the possibility of their application in this work oriented towards agriculture.

As has been shown, agriculture is facing problems due to water management and the cost of purchasing electricity. The work presented in [44] does not evaluate the performance of the blockchain technology applied in support of the community and the possibilities of communication with the blockchain network. The same is approached in [45] in managing the agro-food supply chain through the use of IoT of the consumption data.

How to use a water pumping system in irrigation system is fully described [46]. In this method, the water demands for irrigation are met and qualitatively analyzed, and energy products for 
photovoltaic systems and the surplus of economic energy are redirected to the necessary coverage in the area.

So, an experimental study of renewable energy-based irrigation system is presented here in order to highlight the SCADA interfaces for a farmer and for the association, and the main features and advantages of the implemented blockchain-based application compared with the aforementioned proposals.

The location selected for the study is located in the Oltenia area of Romania, a geographical area where the solar radiation is high, and the quantity of natural water is reduced.

It is an area with low potential both economically and socially. The analyzed area is considered as agricultural area. The cultivation of the land is the main means of existence of most families. According to the [47] existing irrigation system, "it worked partially year after year, in an increasingly advanced state of degradation: pumps and equipment were damaged, they clogged channels, some pipes were stolen directly from the field".

With the help of the World Bank [47] the system was rehabilitated, but even after that it was only partially functioning due to the bureaucratic and impractical way of administration. The electricity subsidy needed to start the pumps, considered state aid, has been canceled since 2010, which has made it impossible for small farmers to bear the costs [47].

This area features a photovoltaic park with high energy efficiency. Nearby there is a system with a non-functional irrigation channel with a high degradation status, which is not currently in use (see Figure 2). Farmers in the area do not have the possibility to use water for crop irrigation during the droughts of the year (spring-summer), even if the channel is supplied with water.

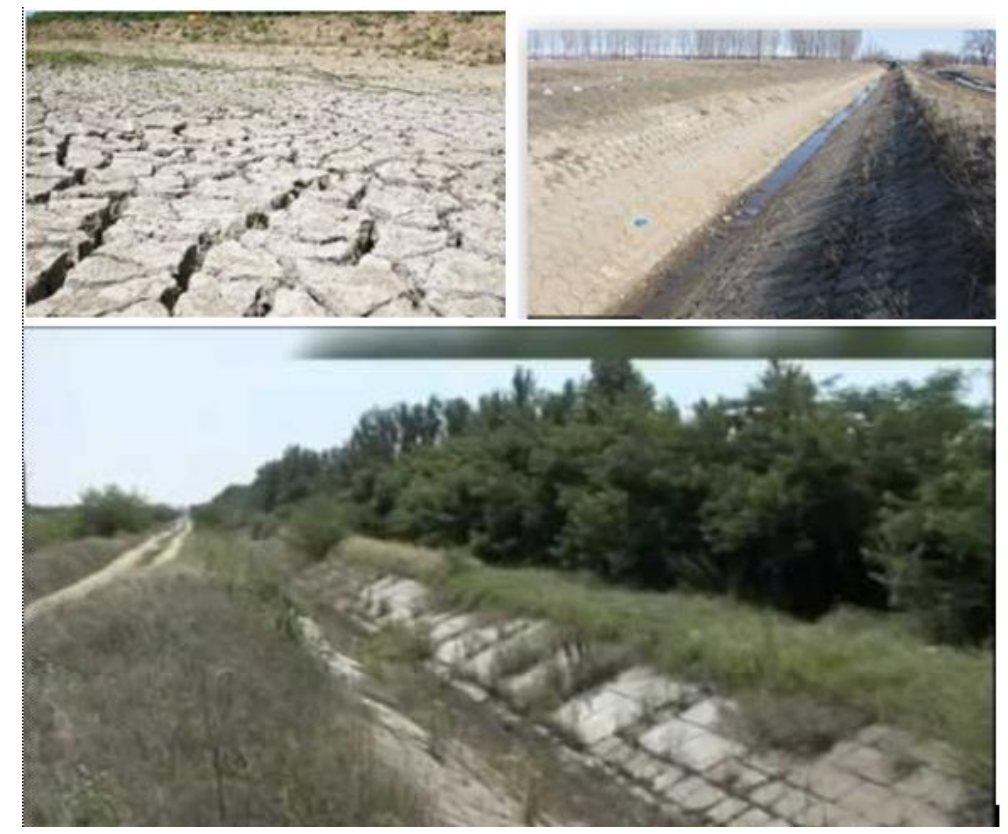

Figure 2. Images from the area where the study has been carried out.

The problem of rehabilitation of the channel and pumping stations has been raised, but the small farmers cannot accept the connection to these systems as the costs of running water in the channel are very high compared to their income. Considering the possibility of using renewable energy through photovoltaic panels, whose costs are in a continuous decline, their concentration in micro grids, and the possibility to establish from the beginning their profitability by tracking the production of the photovoltaic park near the pumping station, three possible irrigation solutions will be explored in this study: 
- Energy supply from the national energy system for land improvements and water supply to small producers;

- Use of the electricity produced by a nearby photovoltaic park, which delivers the energy to the national energy system and this can be used by farmers to supply the water pumps for the rehabilitation of the existing irrigation system;

- Establishing an association to deal with the management and production of electricity with renewable sources and the administration of the existing irrigation channels.

The first solution was already tried in another agricultural area in our country, by rehabilitating an irrigation system with European funds [47]. Considering the data presented in [48] — parliamentary report reveals the deterioration of the irrigation system-it is shown that in terms of the state of the pumping states, "they are mostly inoperative or require rehabilitation of a smaller or greater extent. On the whole of the analyzed areas, only five hours from the pumping stations are functional". It turned out to not be efficient, and the investment could not be amortized as expected. Water can be delivered to farmers, but at a high price. So, individual producers cannot afford it.

Innovations in electronics, information technology, as well as in energy storage solutions, allow the emergence of dispersed energy systems based on unconventional sources. The high costs and the random and intermittent nature of some of these energy sources make some a far-away alternative, or in other words, a possibility only in the future when there is no alternative, and the technologies of capitalization will be much more advanced, and of course, cheaper than they are currently. However, the prospect of capitalizing other forms of energy (unconventional energies) is very close, as they are also the energy hope of mankind. For these reasons, the latter solution is the most advantageous method to be accepted by small farmers and this can be demonstrated with this study.

\section{Comparison of the Advanced Methods for Energy Transaction}

SolarCoin represents an alternative digital coin that uses a Proof-of-Stake blockchain to stimulate solar electricity production [49-51].

The technology allows safe quantification of the amount of energy generated and used. SolarCoin owners-individuals or large solar panels-are proposing to build a currency transaction based on the assumption that electricity produced from solar energy is worth more in the world than its value in traditional energy markets [52-54].

SolarCoin represents tokens emitted in circulation when checking the production of solar energy. They can be traded just as normal cryptocurrency, being available at the moment on four different public crypto-currency exchanges. All the transactions are gathered, checked, and synthesized in specific blocks - which create the blockchain for the SolarCoin. It is a high-trust database underlying the project: A distributed, trustworthy, and verifiable ledger of the total energy produced by PV panels [55-57]. It remunerates the producers of solar power with blockchain-based tokens at a rate of 1 SolarCoin (SLR) for each 1 MWh of produced solar energy [58-60].

The technology behind the project is a POST (Proof of Stake Time) blockchain derived from the Vericoin implementation. Being an alternative to the proof-of-work blockchains, SolarCoin is more efficient than Bitcoin because it requires miners to solve computational puzzles [61-63].

SolarCoin is a zero-charge supplementary recompense, which does not depend on other stimuli that the producers of solar energy could receive (such as grants from the government, fixed green energy prices, tax reductions, green certificates, etc.). Anyone who produces solar energy in order to reduce $\mathrm{CO}_{2}$ gas emissions can be rewarded with SolarCoin $[64,65]$.

\section{A. SolarCoin Economy:}

The holder of a solar power plant is qualified to obtain SolarCoin as a zero-charge recompense for the generation of solar energy. For solar plants with a power of less than $20 \mathrm{~kW}$, the right to coins lies with the consumer of the electricity produced rather than the financial holder [62,63]. 
B. Working principle $[66,67]$ :

Step 1: To qualify for a SolarCoin grant, owners must register their facilities through the SolarCoin Foundation. The registrations can be realized directly on the website of the foundation through a SolarCoin associate or through a tracking program.

The record includes evidence of plant ownership, network connection documentation (verifiable by an independent entity), solar power production parameters (e.g., meter readings), and KYC data (Know-Your-Customer).

Step 2: Upon completion of the registration, the foundation generates SolarCoin to the owner's SolarCoin digital wallet directly.

Step 3: SolarCoin is issued every six months to plant owners who are registered.

So, the SolarCoin will become a good/[an asset] with increasing liquidity, and it will be transparently released and tracked through blockchain, which can be stored in electronic wallets (e.g., mobile devices, computer) or offline (e.g., paper wallets).

Because environmental issues are getting more and more visible through the media (e.g., with the Amazon rainforest fires), green energy is getting more attention. This means more affordable photovoltaic panels, and that the SolarCoin demand and prices might go up in the following years, becoming additional revenue for solar power producers. Owners who generate solar energy could use/sell this energy and also obtain SolarCoin that can be reclaimed, exchanged, or used.

\section{Profit SolarCoin [68]:}

Use of the SolarCoin may be an important stimulant for the investors in solar energy in order to increase the capacity of production. Investors will take the commitment to put money into solar energy by relying on:

1. The price of the installation;

2. The cost of the solar energy it generates;

3. Expected earnings from any additional incentives they receive.

SolarCoin implements the remarkable features of blockchain technology in order to obtain a new situation:

- A supplementary zero-charge reward for solar power producers;

- The first digital coin to preserve natural funds;

- The first stimulus program for solar energy that is non-governmental, global, and decentralized.

Partnerships can also be rewarded with SolarCoin-all contributing to building the ecosystem. SolarCoin ensures the distribution of digital coins to a beneficial and real economic and environmental activity: Vertically produced solar energy. SolarCoin is, thus, able to develop into a special, limitless stimulus for solar energy, independently of any other national or local stimuli [69]. Also, it is worth mentioning that all of the transactions are clear and can be visualized by any user of the blockchain explorer. Due to their distribution, blockchains can diminish the cost and duration of transactions. More significantly, the blockchain technology is prepared to transform the value exchange, eliminating the requirement of having intermediate energy distributors or banks [70-72].

This being the context of the problem, the scope of this study is related to the development of modern land improvement systems at low exploitation prices in order to be accessible to all farmers [73-75]. Table 1 summarizes the main features of purchasing and, in turn, distributing the energy surplus produced in a household/association using photovoltaic panels.

Manufacturers can opt for the method they consider to be the one that can bring them a high profit from an economic point of view. When choosing the optimal solution, the following table might be helpful, but obviously, there are many other details to be taken into consideration, such as the location, the number of possible members of the association, the current status of the nearby irrigation channel, etc. [76-78]. 
Table 1. Characteristics of purchasing energy technologies.

\begin{tabular}{|c|c|c|c|c|c|c|}
\hline Technology Type & $\begin{array}{l}\text { Stimulates } \\
\text { Innovation }\end{array}$ & $\begin{array}{l}\text { Global and } \\
\text { Decentralized }\end{array}$ & $\begin{array}{c}\text { Stimulus } \\
\text { for Solar } \\
\text { Energy }\end{array}$ & $\begin{array}{l}\text { Open-source } \\
\text { Community } \\
\text { Project }\end{array}$ & Reward & Tokens \\
\hline $\begin{array}{l}\text { Photovoltaic plant } \\
\text { connected to the } \\
\text { national power } \\
\text { system }\end{array}$ & NOT & NOT & NOT & NOT & NOT & NOT \\
\hline $\begin{array}{l}\text { Blockchain—utility } \\
\text { tokens }\end{array}$ & YES & YES & NOT & NOT & Tokens & YES \\
\hline Blockchain_SolarCoin & YES & YES & YES & YES & $\begin{array}{l}1 \text { SolarCoin (SLR) } \\
\text { per } 1 \mathrm{MWh} \text { of solar } \\
\text { energy produced }\end{array}$ & NOT \\
\hline
\end{tabular}

The aforementioned features (see Table 1) of the possible implementation solutions are explored in the next sections of this study and compared with the proposed solution.

\section{The model of the Energy Consumption Flow within a Farmers' Association}

The association of farmers in the studied area, in the first stage, will acquire collective energy from the energy suppliers. The greater the participation in this association, the easier it is to estimate the consumption time (due to the law of large numbers) and thus the easier it is to negotiate a discount with the energy provider. At the end of the period, a balance sheet of the consumer profiles of the integrated users will be made. Profit earned by associates can be invested in the next year.

In the next stage, knowing the energy consumption, it is possible to estimate the electric energy needed by the association, and in these conditions, it can be purchased in the case of Romania directly from OPCOM (the Romanian Electricity and Gas Market Operator). Under these conditions, with the classic system, the association can obtain a profit that is invested in the acquisition of renewable sources that lead to independent energy, but also to energy storage solutions.

The solar radiation flux reaching the earth's surface has an energy potential corresponding to the impressive amount of 172 billion GW [79]. This energy source could permanently ensure the need for ever-increasing consumption. However, from a practical point of view, with regards to the actual volume that can be used, this becomes a very complex problem.

Photovoltaic water pumping systems (PWPS) consist of a series of photovoltaic panels, a motor, and a pump (Figure 3). Depending on the design, the system may contain batteries for storing electricity and charging the regulator. The motor is chosen according to the required power and the nature of the current provided by the system. If the motor uses alternating current, it is necessary to install an inverter. PWPS without an energy storage system are cheaper and require less maintenance compared to battery systems. Adding a water storage tank to the PWPS is a more economical method of storing energy than using a battery and useful if irrigation if possible, using gravity afterward. If the tank is built deep, some energy from the PWPS is required to take the water out. Photovoltaic solar energy is considered to be an important resource for regions of Romania where direct solar radiation can reach up to $1000 \mathrm{~W} / \mathrm{m}^{2}$, even if some cost is involved, mostly due to batteries lifespan, panel maintenance (cleaning), and upfront costs [80].

Attention is paid to the daily variation of the volume of water pumped. A threshold value (at which the pump starts/stops) of the total solar irradiance on the surface of the photovoltaic module is set to $450 \mathrm{~W} / \mathrm{m}^{2}$, which means that when the total solar irradiance is less than $450 \mathrm{~W} / \mathrm{m}^{2}$, the pump does not work. It starts at $450 \mathrm{~W} / \mathrm{m}^{2}$ and the water flow increases with the increase of solar irradiance.

At this stage, when $6000 \mathrm{Wh}$ is needed for a pump, the energy produced by the photovoltaic park in the analyzed area can be used. 


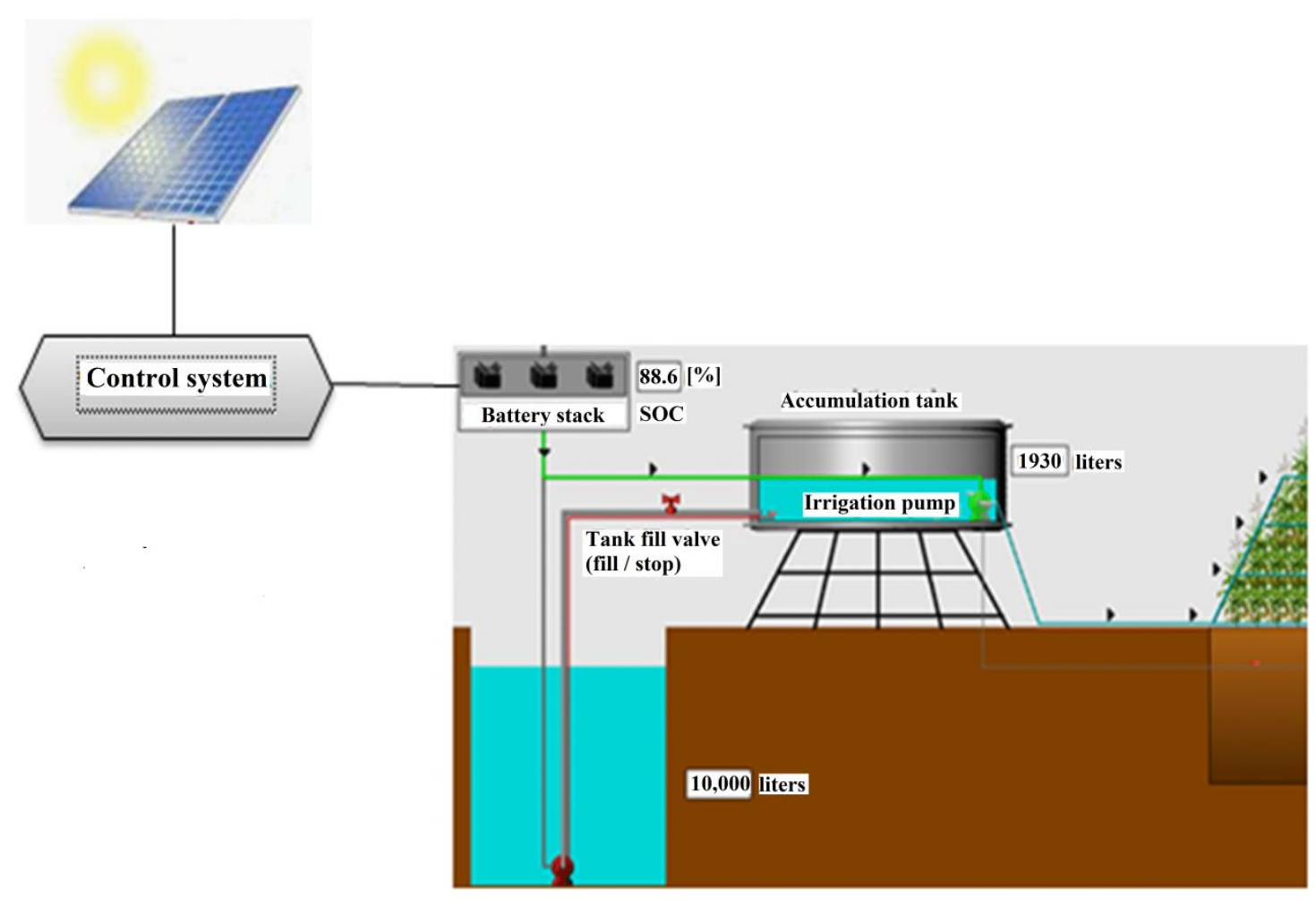

Figure 3. Photovoltaic system for pumping water.

Being a legal entity, the association can build its own photovoltaic park by acquiring photovoltaic panels. In this way, the association will be able to trade the energy produced both to the consumers inside the association and to the association's neighboring consumers. The profit obtained will come in the endowment of the photovoltaic park.

The profit is simply obtained by registering in the SOLARCOIN database, through which each farmer and the respective association can win SolarCoin. These can be purchased and subsequently reinvested, for energy acquisition and other resources. The SolarCoin Foundation will ask for registration data on the purchase of photovoltaic panels, as provided in the operating status [67,68].

The amount of additional energy generated will be sold through the novelty blockchain system. An important objective of the association is the realization of a software application that monitors the performance of each user.

The association is the owner of the equipment that will be given in the form of commodities to the persons in the association on the ground of which they are located. In this case, a solution for optimal land use would be to place the panels above the channel, as well as to hygienically protect the water in the canal.

The unused energy surplus will be traded on behalf of the association to members who, at that time, have an energy demand not covered by their own production or to the national energy system (Energy Distributor) (see Figure 4). 


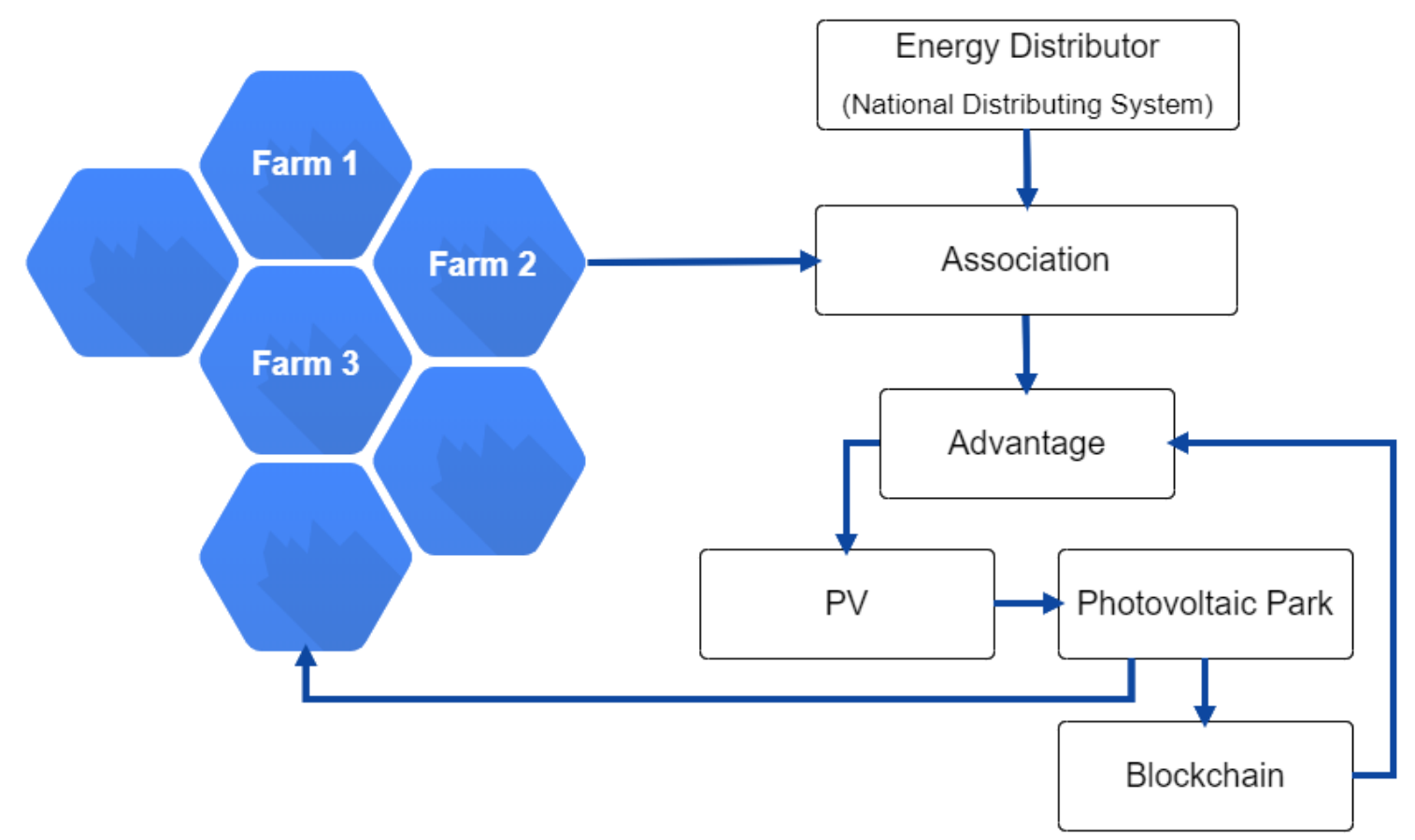

Figure 4. Proposed diagram for the software platform used in the association in order to make the activity profitable.

\section{Experimental Study for an Irrigation System Based on Renewable Energy}

The direct connection of the photovoltaic module to the water pumping system is the cheapest commercial solution. At a high-level description, the system consists of a photovoltaic module directly connected to the DC motor of a centrifugal pump. Due to its simplicity (not including batteries and the control system), such a system is simple and reliable. The pump was monitored for five months, during the spring and summer months when the crops were irrigated, in order to evaluate the volume of pumped water and its distribution over time and the influence of the solar radiation regime on the performance of the system. The first information is essential for photovoltaic system sizing to ensure optimal operation of the water pumping system. The second information may provide an overview on the case study in order to generalize the results obtained.

\section{A. Choosing Panels:}

For each member of the association, the energy requirement for pumping water will be calculated depending on the area owned. In order to determine the number of photovoltaic panels and the total power generated by the photovoltaic system, the steps and relationships mentioned in the Appendix A may be used.

B. SCADA system for association members-users:

The CitectSCADA®software from Schneider Electric has been used to implement the tracking system. A friendly interface (see Figures 5 and 6 ) allows tracking and control of the actual state of the irrigation system by both cultivators and the association.

At the beginning of the study, an isolated agricultural farm was analyzed, from an energy point of view and water supply, equipped with photovoltaic panels to generate the energy required to supply the water pump (depth), which was distributed in the irrigation system. With the help of this interface (see Figure 5), the state of the system can be monitored and controlled, namely: Average temperature, water level in the basin, battery charge level, and soil moisture.

Starting from this, it was continued to reduce costs and increase the reliability of the system. So, these unique farms will be constituted in cooperatives or associations (see Figure 6) that will be able to manage the situation of production, consumption of energy and water, costs, surplus of energy 
realized, when appropriate, not by storage in batteries but by sale (smart contracts and utility token) to other farmers from outside cooperatives, either by feeding the national system.

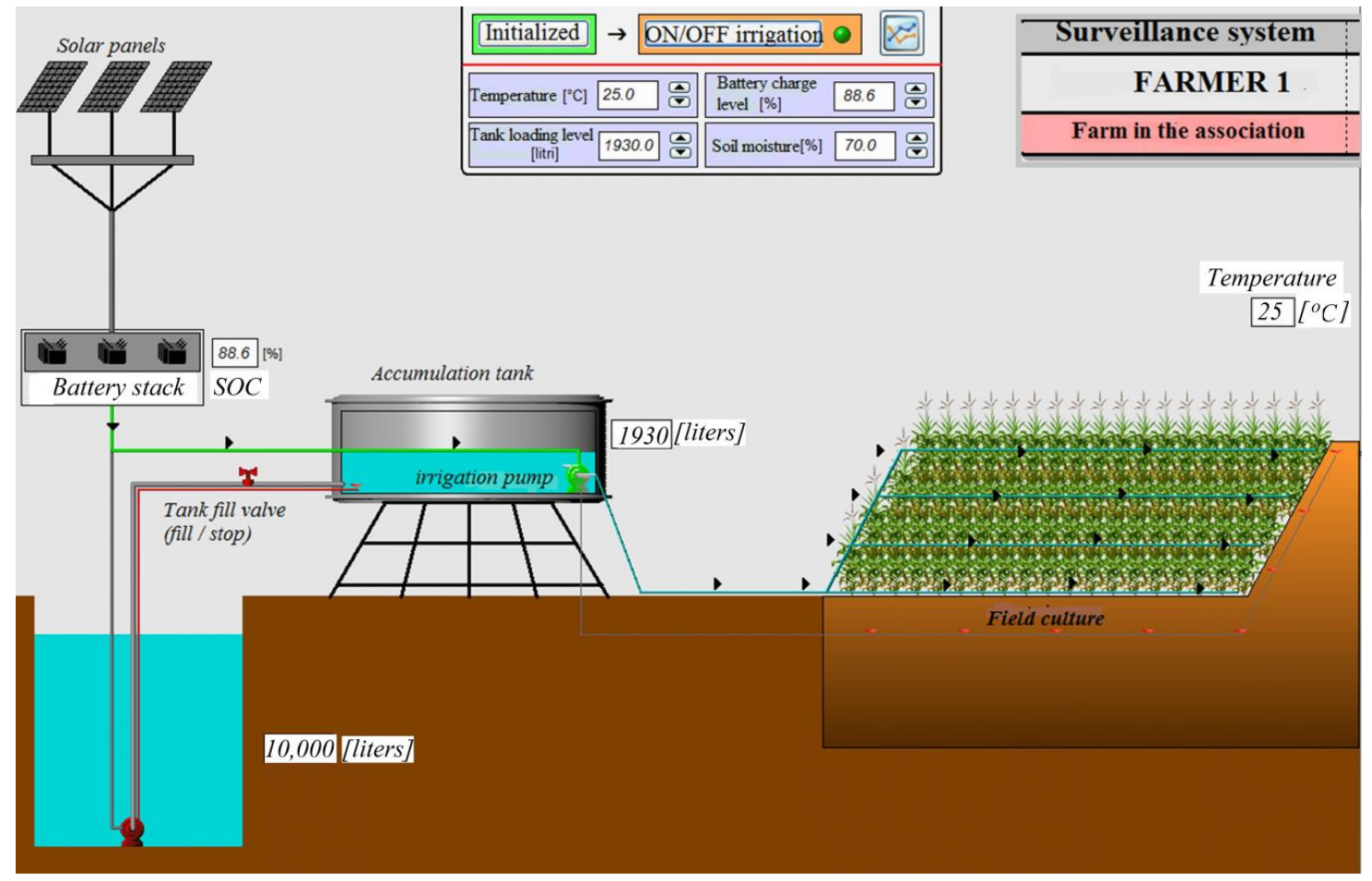

Figure 5. Human-Machine Interface (HMI) Supervisory Control and Data Acquisition (SCADA)-Farmer 1.

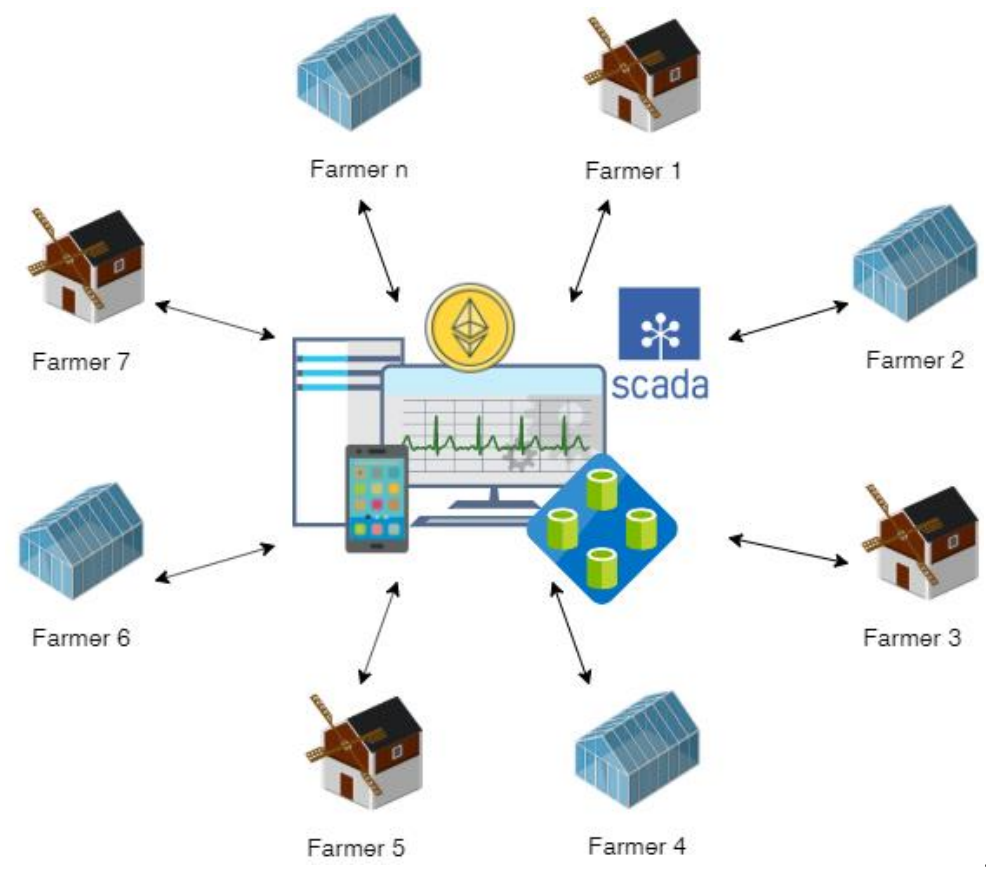

Figure 6. SCADA system at the farmers' association level.

In Figure 6, we can see how the farmers will interact with our proposed system. Basically, the association of farmers will allow members to interact with the platform through the mobile application, which will interact via the backend with the utility token (Ethereum blockchain), distributed database, and the SCADA system for the monitoring and controlling the energy and water. 
In order to have control over the amount of energy produced by the association, but also over the consumption of each member, each of the members will be equipped with a system for tracking and measuring the amount of consumed energy. So, the system will be provided with sensors and a warning system to alert users on the state of humidity and the necessity of watering the crops.

All energy consumption and surplus energy data will be stored in distributed ledger databases. These data will be accessible for both the associate and the association so that each of the two entities knows very well the stage they are in. In this way, each will be able to monitor the quality of the system and correct any losses. The system architecture is shown in Figure 7.

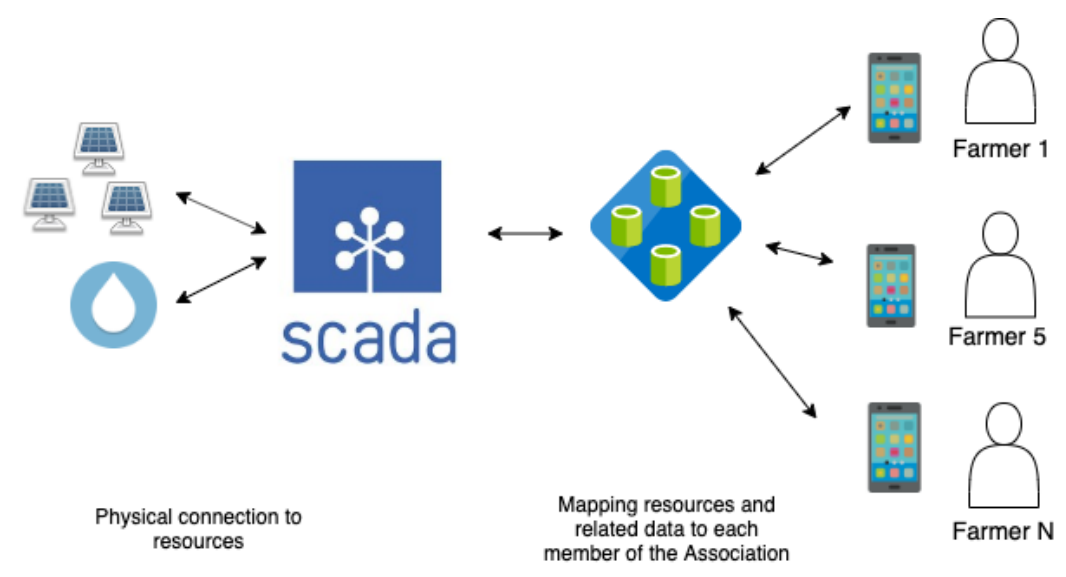

Figure 7. The architecture of the monitoring system—farmers' association.

C. Analysis of the photovoltaic power generation:

In the first phase, if the agricultural association cannot generate enough energy from its own resources, it can resort to the use of green energy resources in the immediate vicinity. At the end of this stage, it can be decided how the profit may be used for the acquisition of photovoltaic panels by the association, in order to create its own photovoltaic park (as it is shown in Figure 4).

A scheme of the proposed working model for the association to make the activity profitable is presented in Figure 8.

\section{Step 1}

In the first stage (first year), in order to be able to carry out its cooperative activity (the association), it acquires the necessary electricity from the national system, until the proposed objectives are achieved. By using the irrigation system, it is obvious that the production and quality of the farmers' products will increase, compared to the incomes obtained before using the irrigation system.

The material advantage obtained will be reinvested in the following year in the acquisition of photovoltaic panels.

Step 2

Near the irrigation channel, a photovoltaic park is located. Considering that this photovoltaic park is located in the studied area, it was possible to track, through the SCADA system existing in the park, the amount of energy produced daily and especially during the spring-summer periods, when the farmers need electricity to supply the pumps.

By realizing the cooperative (the farmers' association), the energy can be negotiated from that existing photovoltaic park or from the stock exchange. In this way, the association can save funds by reducing costs by purchasing electricity.

The money obtained will be invested in the purchase of photovoltaic panels that will be conceded by the farmers from the cooperative, or if the PV purchase will be considerable, it will be made own photovoltaic park. Also, income can be obtained in the form of SolarCoiN, by simply registering in the database, from the respective platform of the PV holders (demonstrating through documents). 


\section{Step 3}

This is the time when the association has its own photovoltaic park, they can produce their own electricity, and therefore the benefits will be great in terms of production costs. With the help of the proposed platform, the surplus of energy, especially the electricity produced in the months in which it is not irrigated, will be delivered (sold) to the farmers outside cooperatives for their own needs or to another association, thus creating a chain of associations. During the periods of the year in which it is not irrigated, the energy will be delivered for cost for domestic purposes.

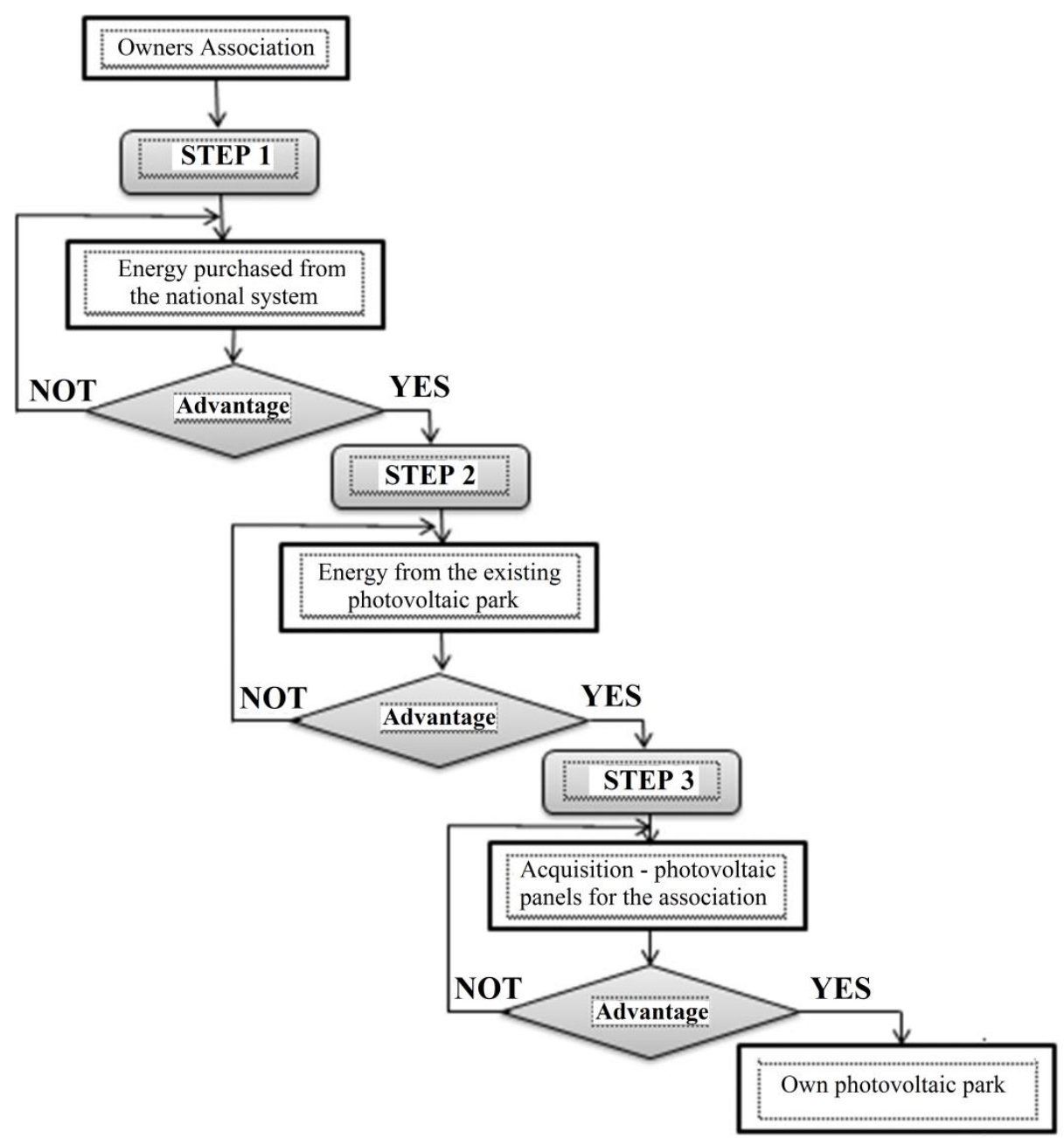

Figure 8. Diagram of the working model for the association.

The availability of energy from the 7.5 MW photovoltaic park (30,646 modules and 14 inverters covering 17 ha in the vicinity of the irrigation channel; see Figure 9) is estimated massed on the energy production budget and performance presented in the Appendix $B$.

The energy production budget for a calendar year is presented in Table A1 and Figures A1 and A2 of the Appendix B based on the values obtained from the SCADA system of the photovoltaic park.

Analyzing the values recorded during the peak months (May-September), when it is necessary to supply the electric power for the pumps from the irrigation system stations, it can be ascertained that they meet the requirements. Also, analyzing the values of the extra-season months, a profit may be obtained by either delivering the energy for the household needs of the members of the association or delivering it into the national energy system (see Figure 10). 


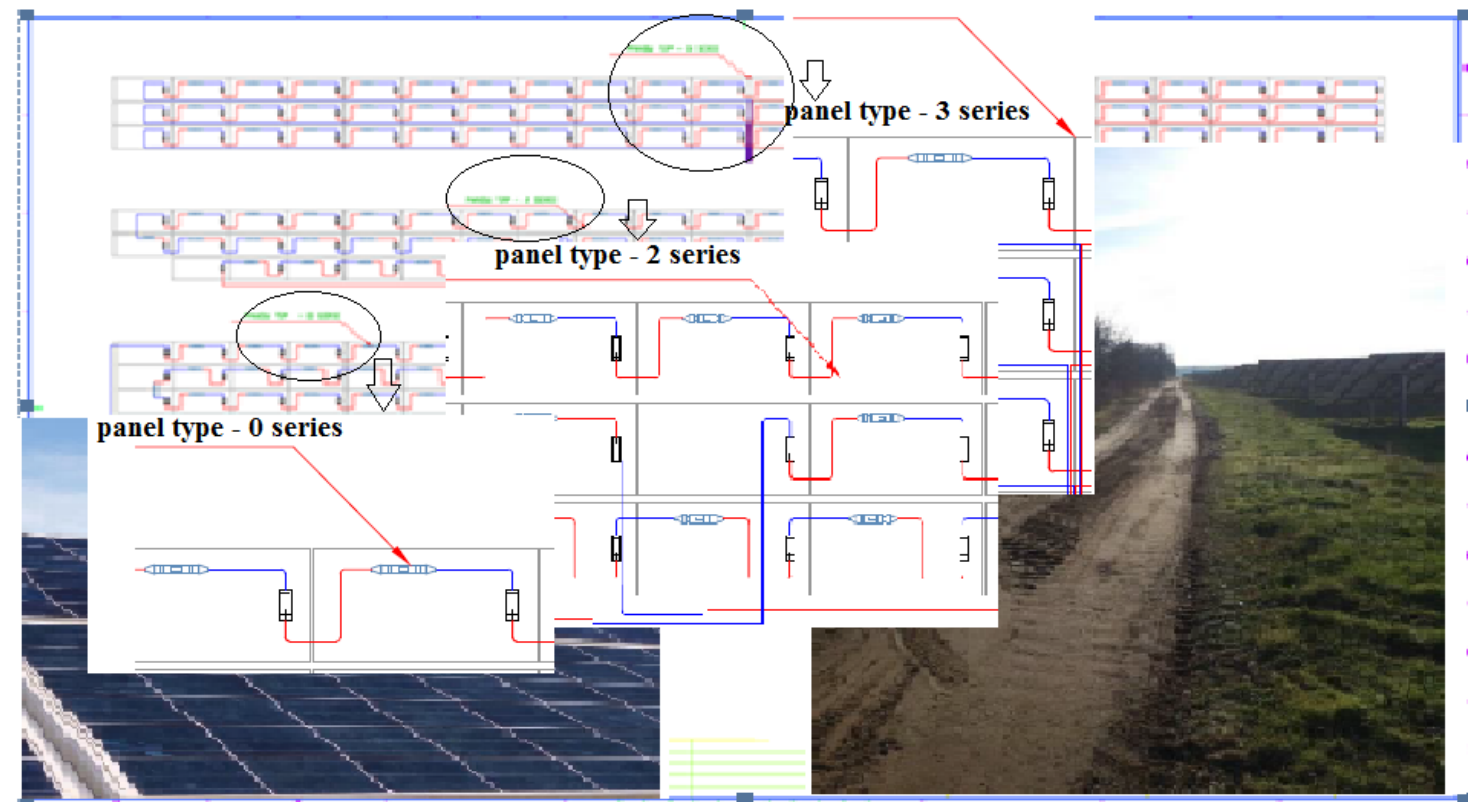

Figure 9. Map of the photovoltaic park.

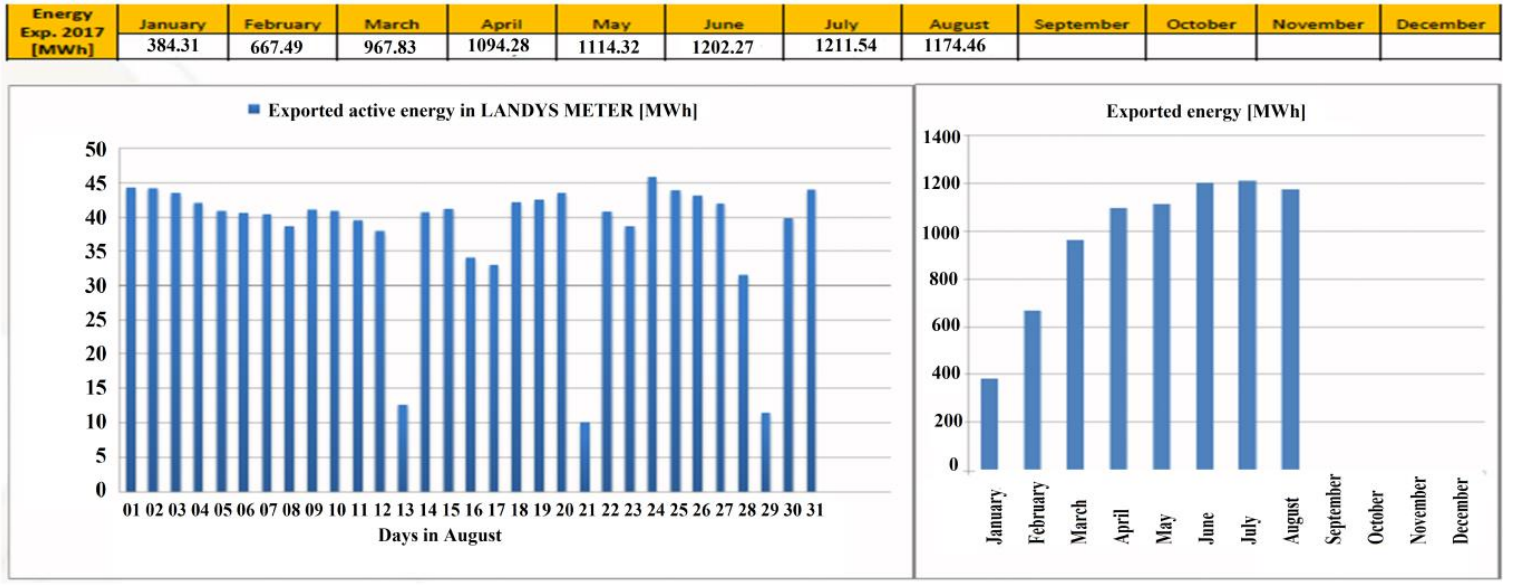

Figure 10. Graph with annual energy production delivered to national energy system.

The performance of the park of photovoltaic panels during time $T\left(P R_{T}\right)$ can be estimated using the relationship (1):

$$
P R_{T}=\frac{\text { Energy produced during a certain period } T[\mathrm{kWh}]}{\frac{\text { Average incident solar radiation during } T}{1000 \mathrm{~W} / \mathrm{m}^{2}} \cdot \text { Peak plant wattage } \cdot T[h]}
$$

For example, the results obtained are presented in Tables A2 and A3 for December, which looks to be the month with the least energy produced (see Figures A3 and A4). This assumption is validated by the energy availability of the photovoltaic park presented in Figure 11. 


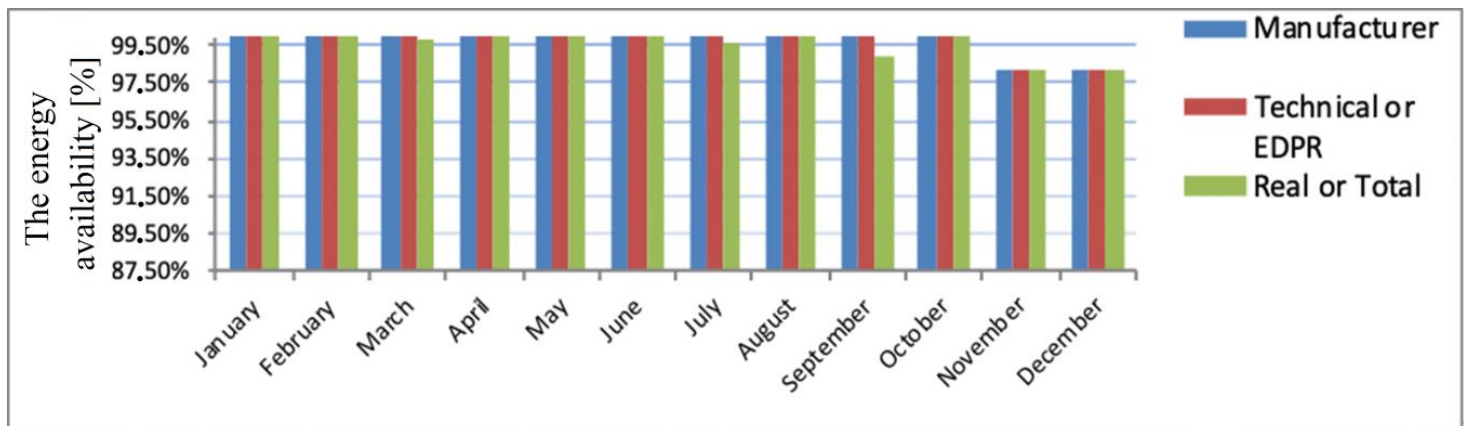

Figure 11. The energy availability of the photovoltaic park.

\section{The Proposed Approach to Reduce Costs}

Considering the solutions presented and discussed in the first part of the study and the need of the small producers to use the irrigation system (and they are aware of this necessity), this study proposes new methods of generating income for producers while keeping low prices for water purchased from the irrigation channels.

Three scenarios have been proposed depending on the area chosen for the study as well as the existing resources. In the proposed methodology, the reduction of costs will be first (see Figure 8). This can be mainly achieved by lowering the energy price using the renewable energy and the proposed method for energy transactions.

\subsection{The System Description}

\subsubsection{Current System}

The current solution (energy supply from the national electricity system) has proven to be unprofitable and thus unacceptable to small farmers due to high costs involved (see the argumentation made in Introduction). So, the energy cost must be reduced by use of renewable energy sources.

\subsubsection{Use of a Photovoltaic Park}

Another solution is to use energy from a photovoltaic park located close to the farms. If the photovoltaic park is equipped with a SCADA system for real-time monitoring and control of the power generation, then the farmers' association can be easily connected and monitored.

The analysis of the data (see the previous section) has shown that such a system is energy efficient but also cost-effective for the owner of this photovoltaic park. However, this solution is not so attractive for the farmers because the energy obtained is delivered at the price set by the distributors.

\subsubsection{Acquisition of Individual Photovoltaic Panel Manufacturers}

So, one of the profitable small businesses of the coming years will be that of small electricity production, due to a continuously growing of energy demand and high prices on the energy market. However, for small energy producers, it is almost impossible to distribute energy and obtain profits because, today, only big manufacturers have access to the energy market. Consequently, only associations of small producers could enter the market (see Figure 12). The local distributor would be obliged to take over the quantity produced by them at a fixed price. The price would be up to $50 \%$ lower than the actual market price.

So, this solution would be advantageous for the small farmer in order to benefit from a considerable profit, but it is difficult to be implemented in this stage. Thus, for a start, a simple and beneficial solution for the farmers' association will be proposed in next section. 


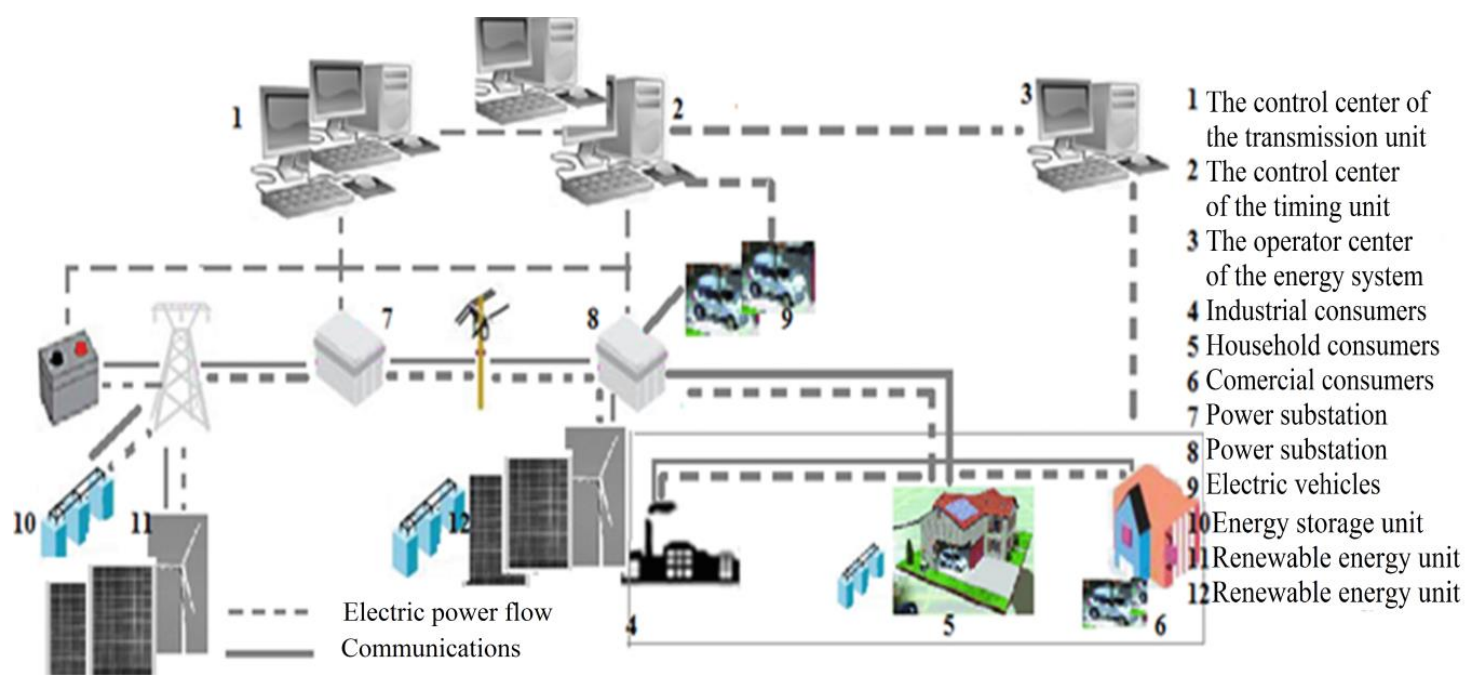

Figure 12. The national power system that integrates the green energy producers.

\subsubsection{Manufacturers Associations}

The small farmers will join an association that will concede the abandoned irrigation channel. The energy produced by photovoltaic panels will be directly used, without being pumped into the national power system and then used.

Equipping the irrigation channels with photovoltaic panels will be done in such a way that the association will make a profit. The association will continue to expand the photovoltaic park in an efficient way, taking into consideration the supply and demand, just like in the market economy. In order not to occupy the land necessary for the agriculture, the water channel can be also covered with floating photovoltaic panels that resist corrosion, and the anchors should last for 25 years or more (see Figure 13).

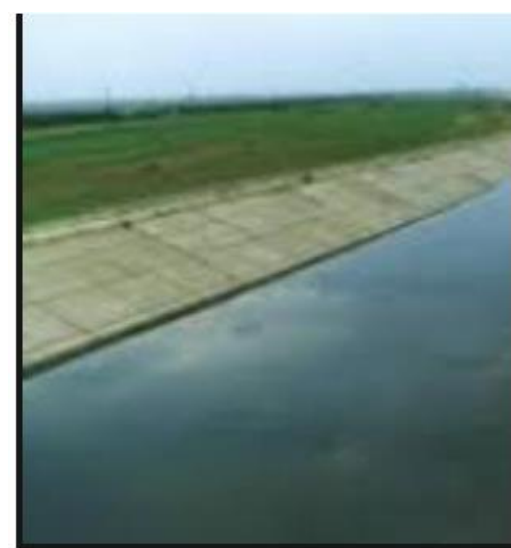

initial

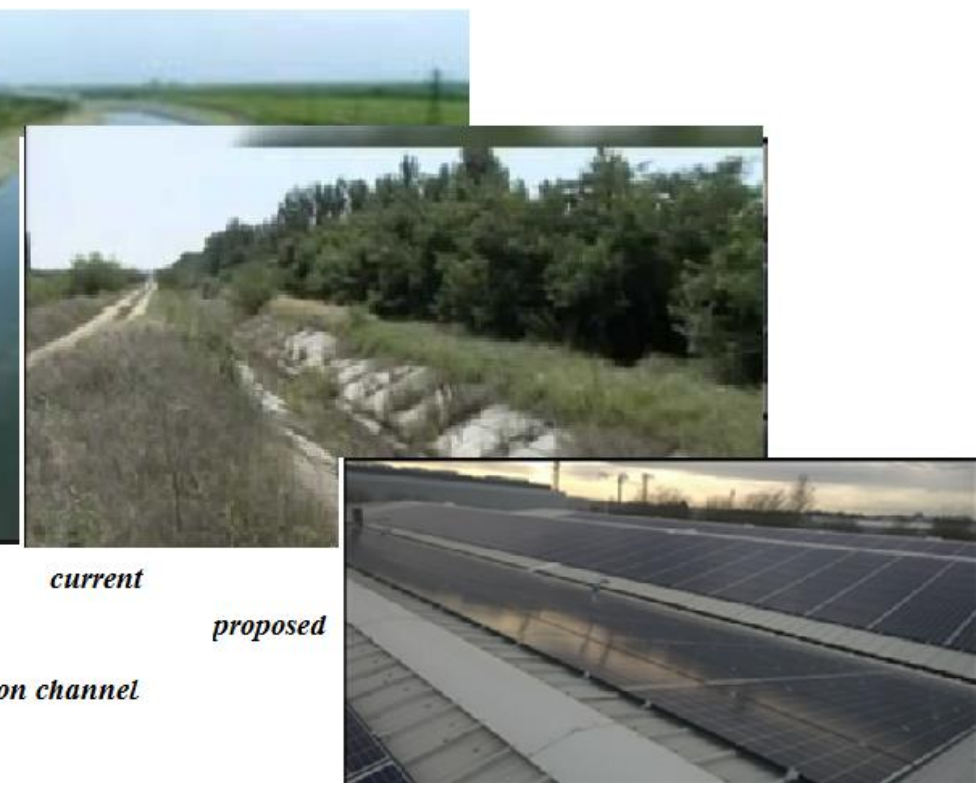

Figure 13. Photovoltaic panels mounted on the irrigation channel.

In comparison with the photovoltaic system mounted on the ground, the photovoltaic system mounted on the surface of the channel has the following advantages:

- $\quad$ The panels do not occupy land; 
- They are not visible;

- The water in the channel cools the solar installation, thus avoiding the overheating that occurs in the case of photovoltaic panels that use silicon components (each module has a maximum power of $200 \mathrm{~kW})$;

- It generates $11-30 \%$ more energy (due to water cooling) than an ordinary "ground" photovoltaic park where the panel can move (more efficient if the panel can move depending on the brightness);

- The floating system is mounted on a light support through which light passes so that the animals in the water can live;

- Reduce water evaporation;

- Inhibit algae inflorescences;

- The colder air reduces the aging of solar cells and obviously increases the performance in operation, granting a longer operating period;

- Requires a smaller cleaning process over time, with a smaller amount of water, than the case of the terrestrial photovoltaic panel [81-83].

The association will be interested in selling the energy surplus, especially in the months when the soil does not need extra water or can be motivated to increase the capacity in order to meet the demand of possible external consumers. Also, some of the energy will be used by association members.

There will be a so-called blockhouse of a restricted community, real-time counting of local energy generation and use, and the analysis of related data. The proposed solution is similar, but more efficient than that proposed in other peer-peer solar energy trading projects, as will be explained below.

\subsection{Blockchain Application for the Association}

The following software solution is proposed for the management of water and energy in an association, which adds a value through the transparency and decentralization of the data. Using blockchain technology, the solution aims to reduce overall costs of irrigation in associations of small farmers. The following components are proposed: A backend application, which processes all the events and transactions and smart contracts; a mobile application, which enables farmers to buy and sell energy and water; and a distributed ledger database, which offers a high degree of transparency and could build trust in the network of farmers in the association.

The detailed components of the platform.

I. The backend module - the backend module will play the main role in the proposed software solution. It will interact with the clients through the mobile application, with the blockchain, and with the databases; SQL and a distributed ledger database (e.g., BigchainDB) will be able to store the accounts (associations and association's members) with all the details such as photovoltaic panels owned, the energy produced, water used, application programming interfaces (APIs) for the mobile applications, SCADA systems, and with the Ethereum main-net blockchain. The Distributed Ledger Technology's (DLT) role is to add a high degree of transparency and to build trust in the network through the decentralization of data.

The administrators of the association can access the backend module trough a web interface in order to set up and configure details such as farmers' accounts, permissions, authentication, etc.

II. The ERC20 utility token-will be created on the Ethereum blockchain using the Solidity programming language. The token will have a fixed total supply and will be used as currency inside the associations to create an internal trading market. Members of the association will be rewarded with the token depending on the amount of energy produced with the owned photovoltaic panels. Buying water from the irrigation channel will also be made using the token.

Farmers will interact with the smart contracts through the mobile application.

III. The Mobile application will be used by the association members to control and monitor the energy produced and the water consumed. Also, it can be used to trade the utility token, allowing households outside of the association to buy water from the irrigation channel (see Figures 14 and 15). 


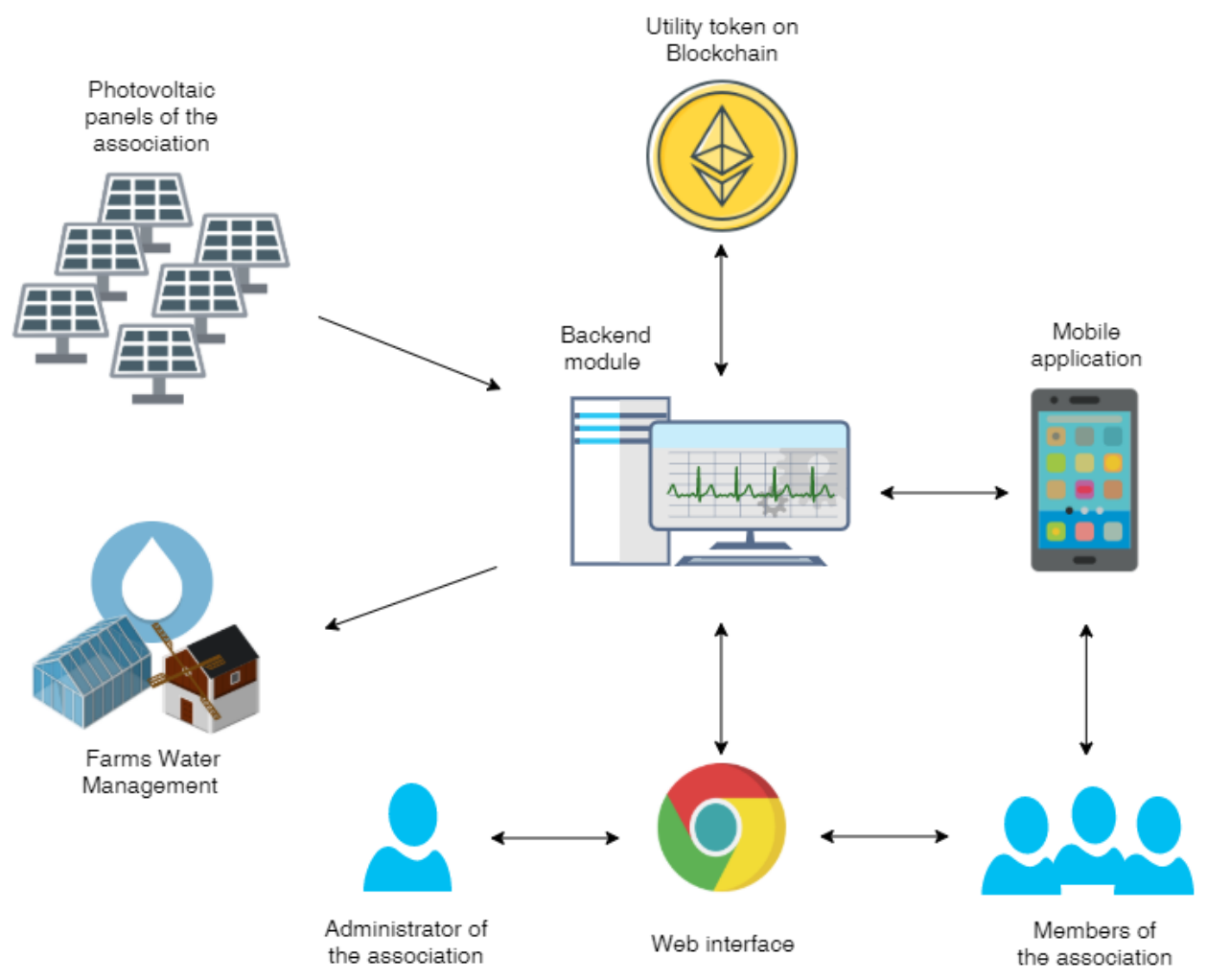

Figure 14. Visual representation of the digital platform proposed.

The architecture of the proposed platform is represented in Figure 14 (high-level) and in the technically detailed diagram from Figure 15. Members of the association (the farmers) will use the mobile application to interact with the utility token (buying and selling the token, energy, and water). The administrators of the association will be able to set up the new members into the system, along with their hardware: Photovoltaic panels and water meters. This will be achieved using the SCADA system and smart waters meters with Ethernet connectivity.

\section{A. Working principle:}

The operating principle is simple to use by a wide range of users.

Step 1: A member of the association will access the platform from a mobile application and will sign into the account. The new members will have the option to create new accounts. A complete set of self-serving features will be implemented.

Step 2: The farmers will fill in the identification data and purchase documents of the photovoltaic panels and after the configuration of the smart water metering and SCADA system, the platform will map to the account the correct amount of energy produced and to all the tokens earned so far. The administrators of the association will enroll the new farmers into the system.

Step 3: Users will be able to spend their tokens via the platform by exchanging tokens for water from irrigation channel, for energy, or simply selling them to the highest bidder (other users of the platform, a member of the association, or to an external user).

Step 4: Users will have the possibility to hide any personal data, and the information stored in the distributed ledger database will contain only pseudorandomized data, following the General Data Protection Regulation (GDPR) accordingly.

After completing these steps, the entire system will be automated by the internal economy created with the help of the utility token. This proposed concept can be used for an association or can be configured for a cluster of associations. At a higher scale, the blockchain will produce even greater benefits as members will be able to avoid energy distributors' costs almost entirely. 


\section{B. Access to data:}

The identity of the owner and the authenticity of photovoltaic acquisition documents are verified through a hash and after that can be accessed by the members of the association, the management of the association, or other interested households.

After enrolling each member in the database, it can access data with daily energy production, the amount of available energy available for sale, daily consumption of households in the association, and households who want to join the association. The same thing goes for the water used or that will be used, and the number of tokens owned by each member.

C. System Automation:

Using the SCADA system and smart water metering solution, the entire system will reach a high level of automation. The operations not automated will be the members enrolling in the system and physically connecting the devices to the irrigation channel.

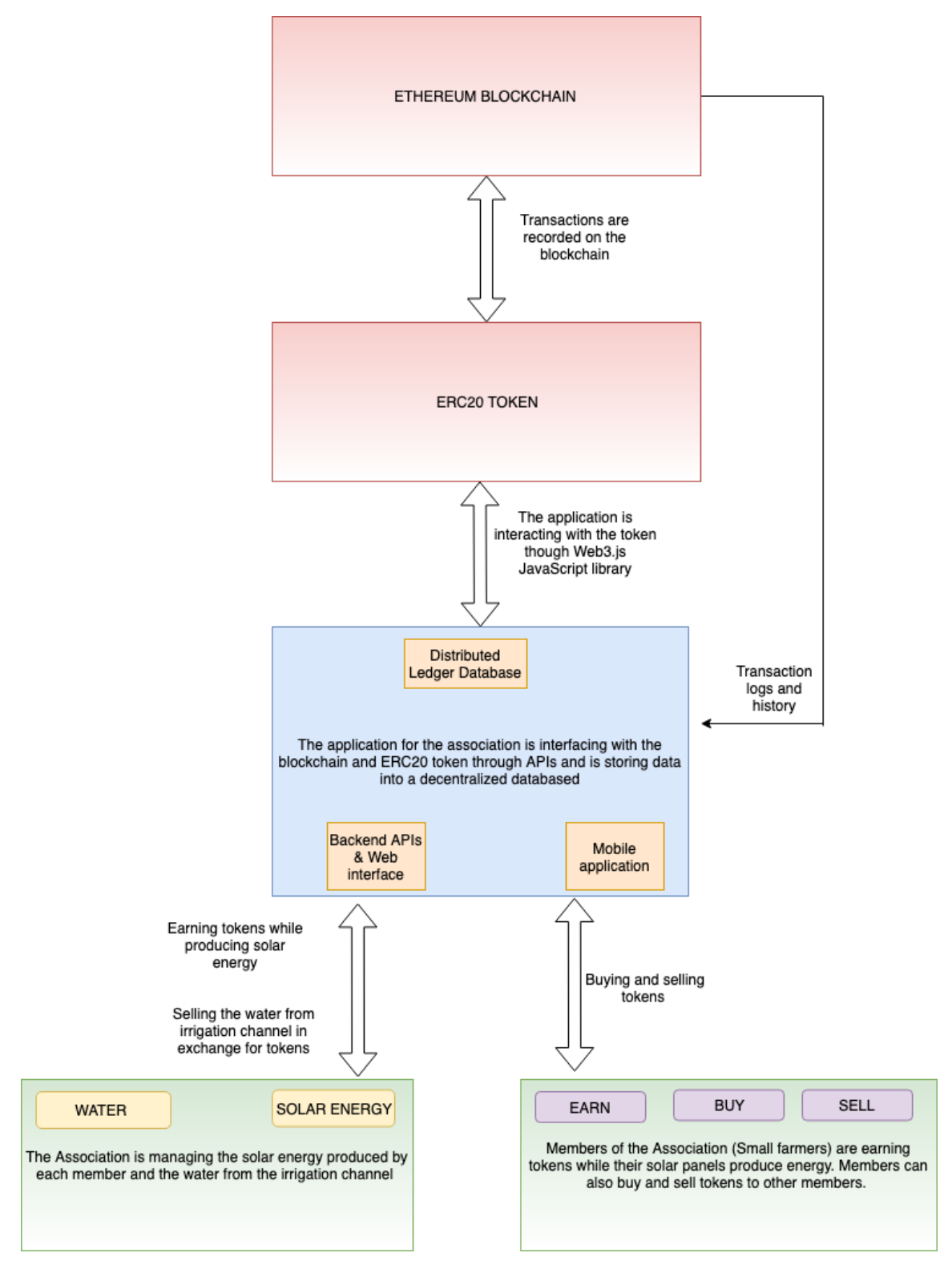

Figure 15. Blockchain-based smart contract system for irrigation systems. 
D. Implementing a prototype and some samples of the obtained results:

In the implemented prototype, an ERC20 token, a basic backend API, and a basic web interface has been developed with the following functionalities: Creating accounts, profiles, and sending and receiving tokens.

(a) Smart Contracts:

The platform interface was built using Truffle framework and web3.js library for interfacing with the Ropsten Ethereum testnet.

The following snippets of code represent the token created using Solidity (Figure 16) and deployment to the testnet blockchain (Figure 17). As it can be observed below, our implementation makes use of the open-source contracts library called Open Zeppelin.

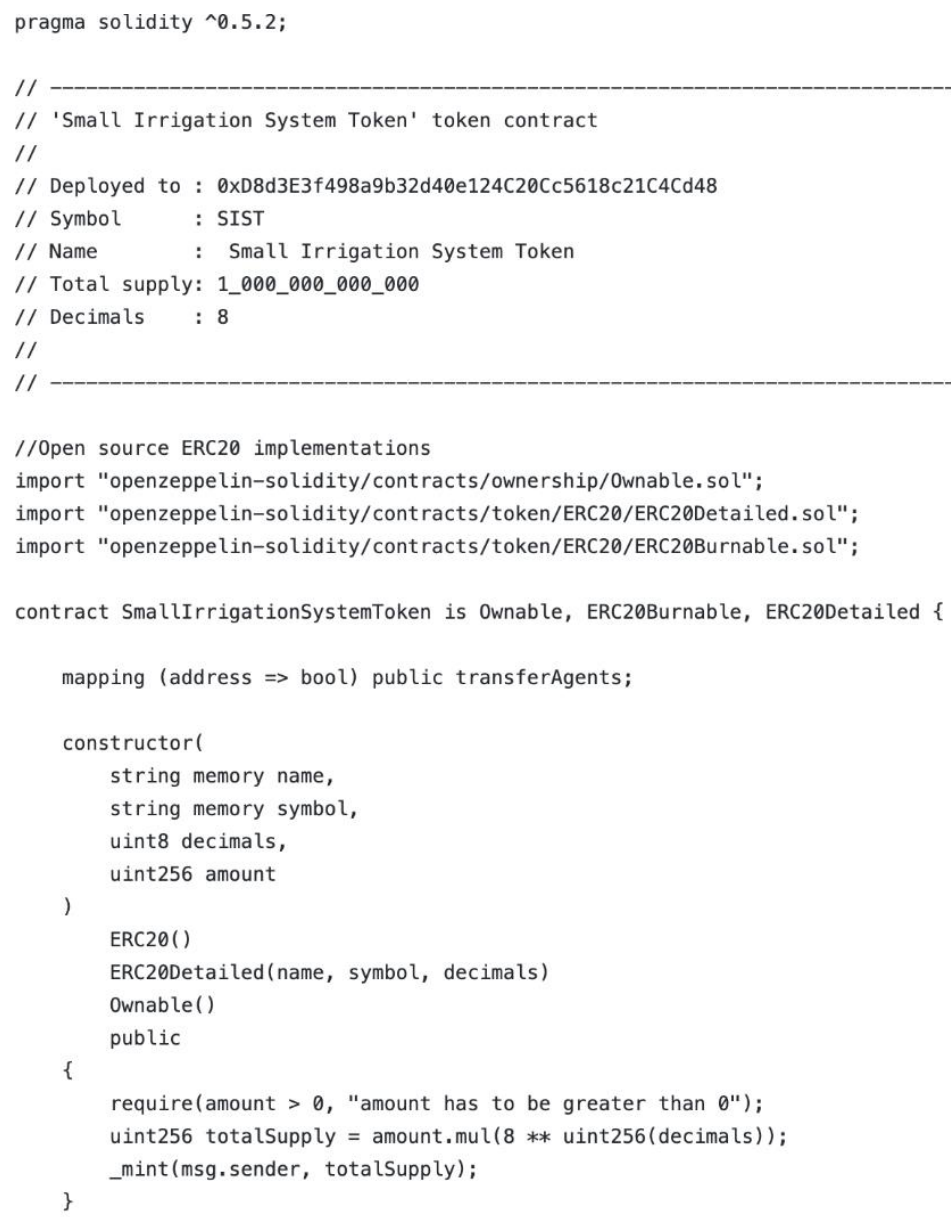

Figure 16. ERC20 implementation of the token's constructor.

The contract developed and deployed as an experiment is named "Small Irrigation System Token" (Figure 16). The constructor is an optional function declared with the constructor keyword, which is executed upon contract creation, and where you can run contract initialization code. The name of the token contract is the long name by which the token contract should be known. The symbol represents the short name by which the token contract should be known; in our case, it is "SIST". Decimals refer to how divisible a token can be, from 0 (not at all divisible) to 18 (maximum Ethereum decimals). The "Amount" defined in the contract refers to the number of tokens that will be minted (created on the first deploy). Contracts used from OpenZeppelin open-source smart contract library are the following: ERC20, ERC20Detailed, and ERC20Burnable; these three offer a secure way of implementing basic token functionalities such as sending and receiving tokens. 


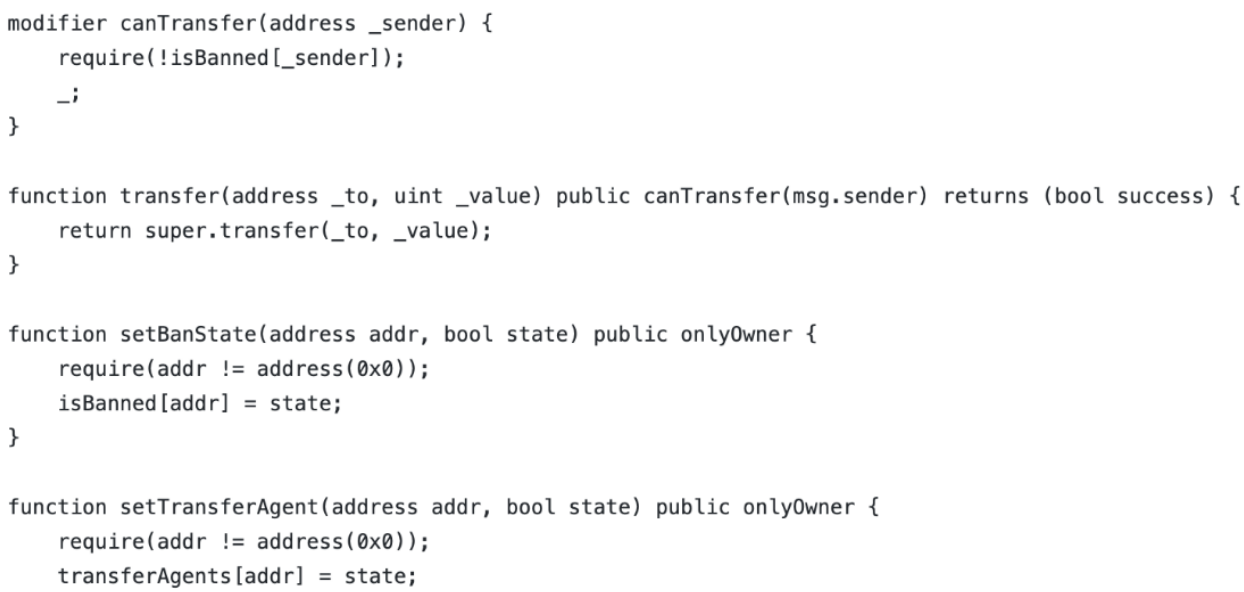

Figure 17. Token's transfer and ban functions.

As a security measure, the association's administrator could make use of the above smart contract functions. The administrator is named by the "setTransferAgent" function and he could deny specific users to use the token. These functions will be called every time a transfer is initiated and will check if the specific account is allowed to make transactions.

(b) Deploy the contract to Ropsten:

The token deployment to the testnet blockchain will be made with the Truffe framework.

1. Build the smart contract with the following console command: truffle buil

2. Deploy the contract: truffle deploy-network ropsten

Once the contract is deployed, the platform can make use of the token enabling transfers between members and exchanges for energy or water. Initial functional and security testing can be achieved using Remix Ethereum IDE.

(c) The interface for the mobile application:

The user interface proposed for the mobile application should be minimalistic and user-friendly, making it very intuitive and easy to use (see Figure 18).

So, the farmers will interact with the platform via the mobile application shown in Figure 17. One of the challenges to be faced will be the quality of user experience and training.

\subsection{Discussion}

After running the experiment, we could create the associations, farmer accounts, simulate energy and water data, and perform transactions via the Ethereum Blockchain. There is a clear set of advantages of the blockchain technology used in associations of small farmers.

- Secure payment and transaction systems based on the blockchain.

- The blockchain technology offers a high level of transparency, as each member of the association can see the number of tokens owned and all transfers.

- Implementing the DLT will enhance the trust in associations, as everyone could see relevant data such as the amount of energy produced and the amount of water consumed.

The next step of the experiment is to integrate the next version of the proposed platform into an association of small farmers. This will help to receive feedback on the user interaction and 
functionalities of the small farmers. Also, the first tests within the association will provide a direction for scaling the platform and supporting transactions between multiple associations or villages and will confirm the effectiveness of developing an internal economy inside the associations. The internal economies will ensure the system is highly performant and is maintained properly even in the winter when the demand for water is not that high. Also, the internal economy needs to reduce the overall cost of irrigation water.

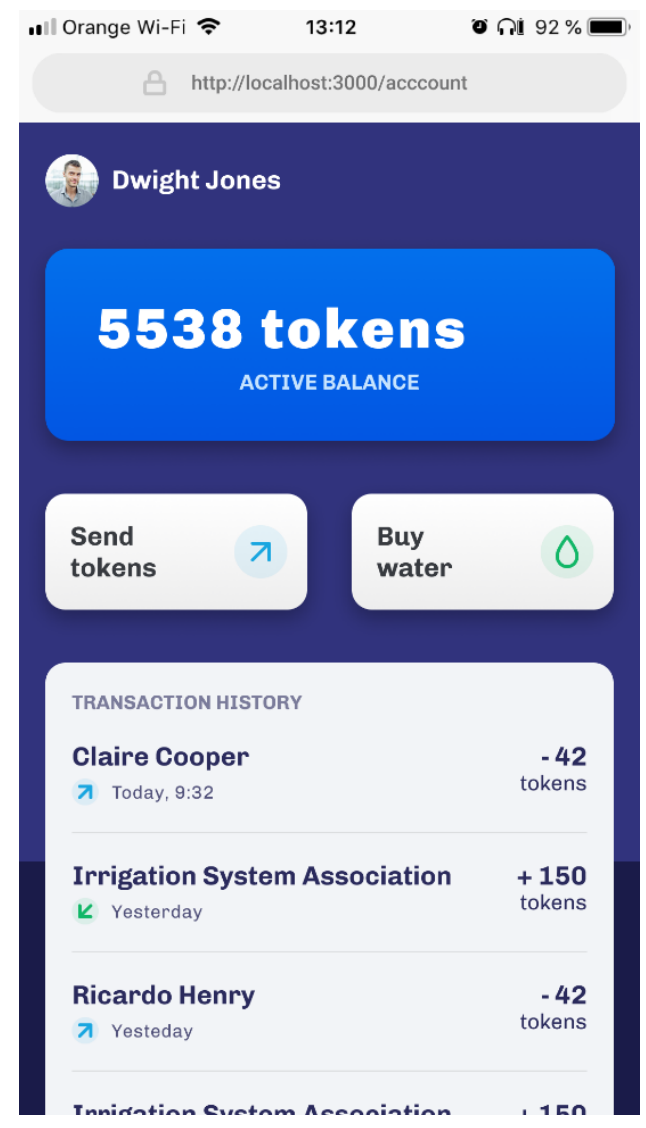

Figure 18. Sample screen of the interface proposed for the mobile application.

Implementing the blockchain-based system in just one association would be the first step in the digital transformation of the irrigation industry and even the solar energy industry. Once this step is confirmed and achieves a good level of adoption, the next step is to enable association-to-association transactions or village-to-village.

\section{Conclusions}

The advantages of the photovoltaic systems for isolated areas without access to the national energy system led to an attempt to propose the rehabilitation of irrigation systems.

The proposed solution is based on creating associations of small farmers that are using the irrigation system connected at photovoltaic panels. The efficiency of the proposed system is monitored not only through the location and type of photovoltaic panels, but also by using the new blockchain technology. Creating an internal economy inside the small farmers association can be a great benefit for the members. Firstly, the token value will be dictated by the demand, offering opportunities for the producers to maintain the infrastructure even in the winter when all the activities in the agriculture industry will be at a low level. Secondly, the non-members interested in acquiring energy or water from the association can make use of the internal economy to get the best price available at that time. 
Innovative and sustainable solutions for agro-power-problems, interchange smoothness, and Human-Machine Interface (HMI) are important contributions of this paper, where the energy efficiency and chain-power-requirements are also considered. To validate the objectives of this study, an experimental renewable energy-based irrigation system with SCADA interfaces based on the proposed blockchain applications has been used.

So, the main findings of this study are as follows:

(1) The advantages of the proposed experimental renewable energy-based irrigation system using the energy of photovoltaic panels and a blockchain-based transaction system have been shown;

(2) The investment can be quickly recovered if a large number of farmers are involved in the same association through this blockchain-based application (see the energy production vs. budget presented during a year);

(3) The comparison of the blockchain utility tokens and SolarCoin technologies has been performed.

From the research, it is fact that the takeover of the agricultural irrigation activity by an association is one of the best solutions for enforcing agricultural production, but also for getting benefits from the community by reducing the costs of electricity in part or in some cases totally. An important profit is also obtained by selling the surplus energy you get.

Also, it should not be forgotten that a decommissioned and uncleaned channel can be rehabilitated to become functional.

Author Contributions: Conceptualization, methodology, and writing—original draft preparation: F.M.E. and N.B.; validation and supervision: A.O.; formal analysis: M.S.R.; writing-review and editing: N.B., P.T., G.S., and A.G.M. All authors have read and agreed to the published version of the manuscript.

Funding: This work was partially funded by Research Center "Modeling and Simulation of the Systems and Processes" based on grants of the Ministry of National Education and Ministry of Research and Innovation, CNCS/CCCDI-UEFISCDI within PNCDI III "Increasing the institutional capacity of bioeconomic research for the innovative exploitation of the indigenous vegetal resources in order to obtain horticultural products with high added value" PN-III P1-1.2-PCCDI2017-0332. This work was also funded in part by King Mongkut's University of Technology North Bangkok. Contract no. KMUTNB-63-KNOW-040. The APC was free of charge, being an invited paper for the special issue in Sustainability: "Efficiency and Sustainability of the Distributed Renewable Hybrid Power Systems Based on the Energy Internet, Blockchain Technology and Smart Contracts".

Conflicts of Interest: The authors declare no conflict of interest.

\section{Abbreviations}

$\begin{array}{ll}\text { DLT } & \text { Distributed Ledger Technology } \\ \text { GDPR } & \text { General Data Protection Regulation } \\ \text { HMI } & \text { Human-Machine Interface } \\ \text { KYC } & \text { Know-Your-Customer } \\ \text { OPCOM } & \text { The Romanian Electricity and Gas Market Operator } \\ \text { PR } & \text { The performance of the photovoltaic park during T period } \\ \text { PV } & \text { Photovoltaic } \\ \text { PWPS } & \text { Photovoltaic Water Pumping Systems } \\ \text { POST } & \text { Proof of Stake Time } \\ \text { SQL } & \text { Structured Query Language } \\ \text { SLR } & \text { SolarCoin } \\ \text { SCADA } & \text { Supervisory Control and Data Acquisition }\end{array}$

\section{Appendix A}

Design of the photovoltaic system:

The number of photovoltaic panels can be established using the following steps and relationships:

1. Calculate the energy needed to charge the batteries:

$$
\eta_{B A T T E R Y}=0.7 \Rightarrow W_{1}=\frac{W_{D A Y}}{\eta_{B A T T E R Y}}=\frac{3529.41}{0.7}=5042.01 \mathrm{Wh}
$$


2. Determine of the energy required to be supplied daily:

$$
\eta_{\text {BATTERY_CHARGER }}=0.85 \Rightarrow W_{2}=\frac{W_{1}}{\eta_{\text {BATTERY_CHARGER }}}=\frac{5042.01}{0.85}=5931.78 \mathrm{Wh}
$$

3. Evaluate the power of a module:

$$
\left.\begin{array}{c}
\eta_{\text {panelFV }}=0.9 \\
P=190 \mathrm{~W}
\end{array}\right\} \Rightarrow P_{\text {REALmode }}=P_{F V} \cdot \eta_{\text {panelFV }}=190 \cdot 0.9=171 \mathrm{~W}
$$

4. Estimate the average number of hours for standard illumination (hours/day) for the least favorable month (December):

$$
N_{\text {HOURSenviroment }}=6 \text { hours }
$$

5. Estimate the energy obtained per day:

$$
W_{\text {dayFV }}=P_{\text {REALmode }} \cdot N_{\text {HOURSenviroment }}=171 \cdot 6=1026 \mathrm{Wh}
$$

where: $P_{F V}$-the power of a photovoltaic panel; $\eta_{\text {panelFV }}$-the yield of a photovoltaic panel. $N_{\text {HOURSenviroment }}$-the approximate illumination time.

6. Calculate the number of needed PV modules:

$$
N_{\text {MODULES }}=\frac{W_{4}}{W_{\text {dayFV }}}=\frac{5931.78}{1026}=5.78 \text { panels } \approx 6 \text { panels }
$$

7. Calculate the number of modules in series for $U n=24 \mathrm{~V}$ :

$$
N_{\text {seriesMODULES }}=\frac{U_{n}}{V_{m p}}=\frac{24}{35.8}=0.67 \approx 1 \text { piece }
$$

8. Calculate the number of modules in parallel:

$$
N_{\text {parallelMODULES }}=\frac{N_{\text {MODULES }}}{N_{\text {seriesMODULES }}}=\frac{6}{1}=6 \text { pieces }
$$

9. Calculate the number of modules needed to be purchased:

$$
N_{\text {MODULES }}=N_{\text {seriesMODULES }} \cdot N_{\text {parallelMODULES }}=1 \cdot 6=6 \text { pieces }
$$

10. Estimate the total power generated by the photovoltaic system:

$$
P_{N}=190 \mathrm{~W}(\text { from datasheet }) \Rightarrow P_{\text {TOTAL }}=N_{\text {MODULES }} \cdot P_{N}=6 \cdot 190=1140 \mathrm{~W}
$$

\section{Appendix B}

The energy production budget and performance of the 7.5 MW photovoltaic park:

Table A1. Production budget.

\begin{tabular}{lll}
\hline & Monthly (MWh) & Cumulative (MWh) \\
\hline January & 386.81 & 386.81 \\
February & 520.76 & 907.57 \\
March & 882.30 & 1789.88 \\
April & 943.31 & 2733.18 \\
May & 1102.99 & 3836.17 \\
June & 1086.91 & 4923.08 \\
July & 1204.52 & 6127.59 \\
August & 1141.43 & 7269.02 \\
September & 1017.09 & 8286.11 \\
October & 776.11 & 9062.22 \\
November & 463.85 & 9526.07 \\
December & 407.93 & 9934.00 \\
\hline
\end{tabular}




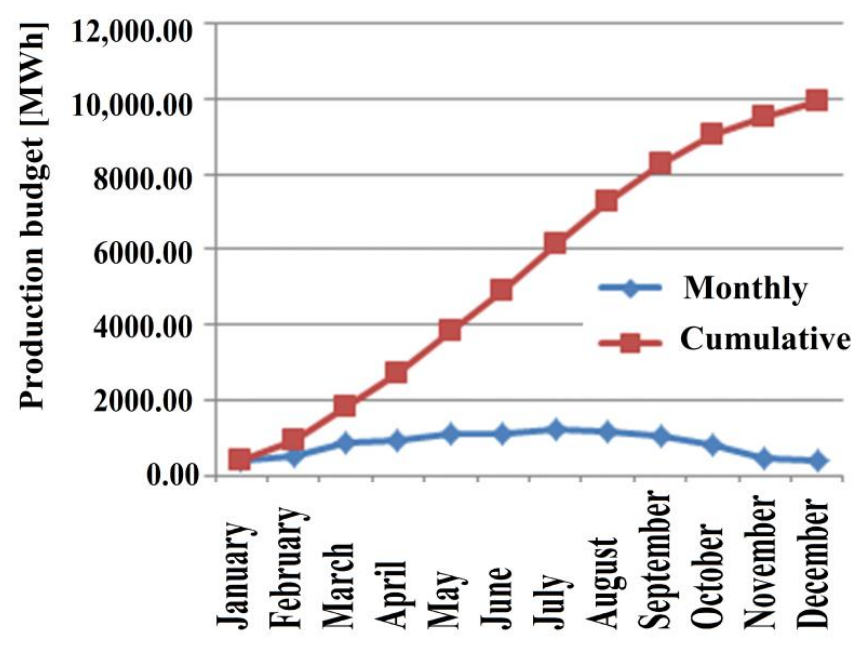

Figure A1. Graph with solar photovoltaic production (MWh) each month of one year and cumulatively from the beginning of the calendar year.

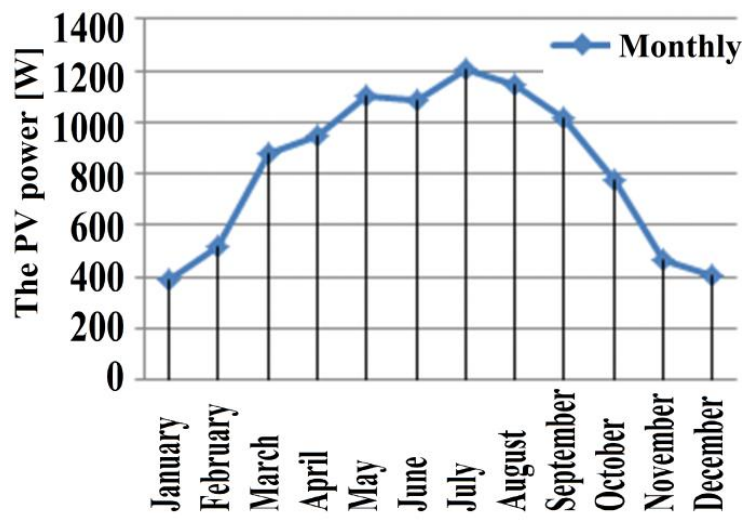

Figure A2. Monthly energy production (MWh) of the photovoltaic park.

Table A2. Energy production in December.

\begin{tabular}{lll}
\hline & \multicolumn{2}{c}{ Production (MWh) } \\
\hline Source & December & Cumulative \\
\hline SCADA [MWh] & 437.93 & $10,209.23$ \\
Meter [MWh] & 505.45 & $10,584.23$ \\
|Difference| [MWh] & 67.97 & 375.00 \\
Dev. SCADA vs. Meter [\%] & 13.45 & 3.54 \\
\hline
\end{tabular}

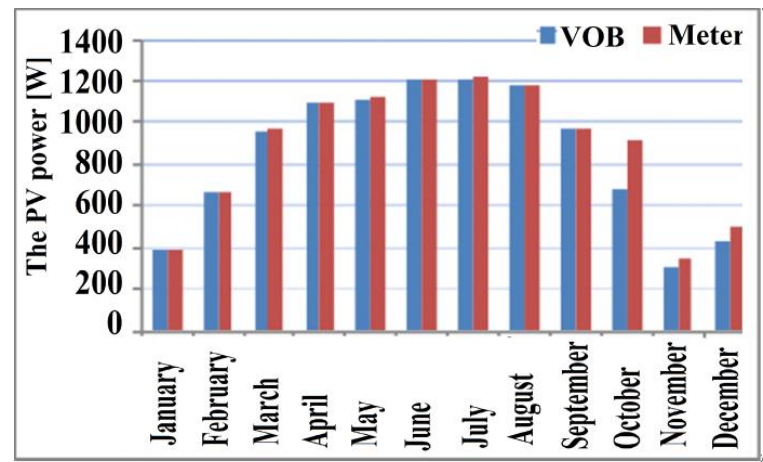

Figure A3. Production representation (MWh)-SCADA vs. meter. 
Table A3. Production-meter vs. budget.

\begin{tabular}{cll}
\hline & \multicolumn{2}{c}{ Production Status: Real vs. Budget } \\
\hline Source & \multicolumn{1}{c}{ December } & Cumulative \\
\hline SCADA [MWh] & 407.93 & 9934.00 \\
|Difference Meter| [MWh] & 97.52 & 650.23 \\
Dev. Meter [\%] & 23.21 & 6.55 \\
\hline
\end{tabular}

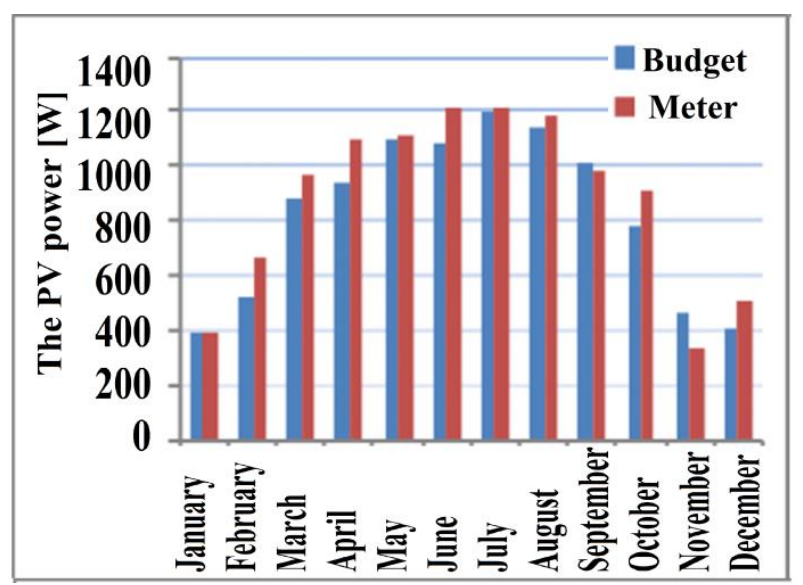

Figure A4. Production representation (MWh)—-meter vs. budget.

\section{References}

1. Agri-Environmental Indicator-Irrigation. Available online: https://ec.europa.eu/eurostat/statisticsexplained/ (accessed on 1 September 2019).

2. Wu, J.; Tran, N.K. Application of Blockchain Technology in Sustainable Energy Systems: An Overview. Sustainability 2018, 10, 3067. [CrossRef]

3. Water for Agriculture. Available online: https://www.eea.europa.eu (accessed on 1 September 2019).

4. Galindo, J.; Torok, S.; Salguero, F.; de Campos, S.; Romera, J.; Puig, V. Optimal Management of Water and Energy in Irrigation Systems: Application to the Bardenas Canal. IFAC Pap. Online 2017, 50, 6613-6618. [CrossRef]

5. Daud, A.K.; Mahmoud, M.M. Solar powered induction motor-driven water pump operating on a desert well, simulation and field tests. Renew. Energy 2015, 30, 701-714. [CrossRef]

6. Bizon, N. Energy Harvesting from the Partially Shaded Photovoltaic Systems-Chapter 7. In Optimization of the Fuel Cell Renewable Hybrid Power Systems; Springer: New York, NY, USA, 2017; pp. 285-301.

7. Shinde, V.B.; Wandre, S.S. Solar photovoltaic water pumping system for irrigation: A review. Afr. J. Agric. Res. (AJAR) 2015, 10, 2267-2273.

8. Babkir, A. Comparative assessment of the feasibility for solar irrigation pumps in Sudan. Renew. Sustain. Energy Rev. 2018, 81, 413-420. [CrossRef]

9. Nallapaneni, M.K.; Jayanna, K.; Mallikarjun, P. Floatovoltaics: Towards improved energy efficiency, land and water management. Int. J. Civ. Eng. Technol. (IJCIET) 2018, 9, 1089-1096.

10. Wattana, V.; Tharwon, A.; Danupol, H. When blockchain meets Internet of Things: Characteristics, challenges, and business opportunities. J. Ind. Inf. Integr. 2019. [CrossRef]

11. O'Dwyer, E.; Panb, I.; Acha, S.; Shah, N. Smart energy systems for sustainable smart cities: Current developments, trends and future directions. Appl. Energy 2019, 237, 581-597. [CrossRef]

12. Hua, H.; Qin, Y.; Hao, C.; Cao, J. Optimal energy management strategies for energy Internet via deep reinforcement learning approach. Appl. Energy 2019, 239, 598-609. [CrossRef]

13. Hirsch, A.; Parag, I.; Guerrero, J. Microgrids: A review of technologies, key drivers, and outstanding issues. Renew. Sustain. Energy Rev. 2018, 90, 402-411. [CrossRef]

14. Reka, S.; Dragicevic, T. Future effectual role of energy delivery: A comprehensive review of Internet of Things and smart grid. Renew. Sustain. Energy Rev. 2018, 91, 90-108. [CrossRef] 
15. Zha, X.; Ni, W.; Wang, X.; Liu, R.P.; Guo, Y.J.; Niu, X.; Zheng, K. The impact of link duration on the integrity of distributed mobile networks. IEEE Trans. Inf. Forensics Secur. 2018, 13, 2240-2255. [CrossRef]

16. Li, Z.; Bahramiradb, S.; Paasob, A.; Yan, M.; Shahidehpour, M. Blockchain for decentralized transactive energy management system in networked microgrids. Electr. J. 2019, 32, 58-72. [CrossRef]

17. Karavas, C.S.; Arvanitis, K.; Papadakis, G. A Game Theory Approach to Multi-Agent Decentralized Energy Management of Autonomous Polygeneration Microgrids. Energies 2017, 10, 1756. [CrossRef]

18. Cioara, T.; Anghel, I.; Bertoncini, M.; Salomie, I.; Arnone, D.; Mammina, M.; Velivassaki, T.H.; Antal, M. Optimized Flexibility Management enacting Data Centres Participation in Smart Demand Response Programs. Future Gener. Comput. Syst. 2018, 78, 330-342. [CrossRef]

19. Islam, R.; Sarker, P.C.; Subarto Kumar Ghosh, S.K. Prospect and advancement of solar irrigation in Bangladesh: A review. Renew. Sustain. Energy Rev. 2017, 77, 406-422. [CrossRef]

20. Ding, W.; Wang, G.; Xu, A.; Chen, H. Research on Key Technologies and Information Security Issues of Energy Blockchain. Zhongguo Dianji Gongcheng Xuebao/Proc. Chin. Soc. Electr. Eng. (CSEE) 2018, 38, 1026-1034.

21. Dorri, A.; Kanhere, S.S.; Jurdak, R.; Gauravaram, P. Blockchain for IoT security and privacy: The case study of a smart home. In Proceedings of the 2017 IEEE International Conference on Pervasive Computing and Communications Workshops (PerCom Workshops), Kona, HI, USA, 13-17 March 2017; pp. 618-623. [CrossRef]

22. Kiayias, A.; Russell, A.; David, B.; Oliynykov, R. Ouroboros: A provably secure proof-of-stake blockchain protocol. In Proceedings of the CRYPTO 2017, 37th Annual International Cryptology Conference, Santa Barbara, CA, USA, 20-24 August 2017; Springer: New York, NY, USA, 2017; pp. 357-388.

23. Wang, X.; Yang, W.; Noor, S.; Chen, C.; Guoc, M.; van Dam, K.H. Blockchain-based smart contract for energy demand management. Energy Procedia 2019, 158, 2719-2724. [CrossRef]

24. Hertig, A. How Do Ethereum Smart Contracts Work? 2018. Available online: https://www.coindesk.com/ information/ethereum-smart-contracts-work/ (accessed on 1 September 2019).

25. Li, Y.; Yang, W.; He, P.; Chen, C.; Wang, X. Design and management of a distributed hybrid energy system through smart contract and blockchain. Appl. Energy 2019, 248, 390-405. [CrossRef]

26. Hassan, M.U.; Rehmani, M.H.; Chen, J. Privacy preservation in blockchain based IoT systems: Integration issues, prospects, challenges, and future research directions. Future Gener. Comput. Syst. 2019, 97, 512-529. [CrossRef]

27. Makhdoom, I.; Abolhasan, M.; Abbas, H.; Ni, W. Blockchain's adoption in IoT: The challenges, and a way forward. J. Netw. Comput. Appl. 2019, 125, 251-279. [CrossRef]

28. Novo, O. Blockchain meets IoT: An architecture for scalable access management in IoT. IEEE Internet Things J. 2018, 5, 1184-1195. [CrossRef]

29. Liu, N.; Yu, X.; Wang, C.; Li, C.; Ma, L.; Lei, J. An Energy Sharing Model with Price-based Demand Response for Microgrids of Peer-to-Peer Prosumers. IEEE Trans. Power Syst. 2017, 32, 3569-3583. [CrossRef]

30. Unguru, M. Blockchain Technology: Opportunities for the Energy Sector. Available online: http://www.nos. iem.ro/handle/11748/1279 (accessed on 30 January 2020).

31. Wang, T.; Zheng, Z.; Rehmani, M.H.; Yao, S.; Huo, Z. Privacy preservation in big data from the communication perspective-A survey. IEEE Commun. Surv. Tutor. 2019, 21, 753-778. [CrossRef]

32. Viji Priya, G.; Krishna Priya, G.; Vivek, M.; Ashwini, R. A survey on security attacks and challenges in bitcoin. Int. J. Comput. Eng. Technol. (IJCET) 2018, 9, 65-74.

33. Conti, M.; Kumar, E.S.; Lal, C.; Ruj, S. A survey on security and privacy issues of bitcoin. IEEE Commun. Surv. Tutor. 2019, 20, 3416-3452. [CrossRef]

34. Nakamoto, S. Bitcoin: A Peer-to-Peer Electronic Cash System. 2008. Available online: https://bitcoin.org/ bitcoin.pdf (accessed on 1 September 2019).

35. Ateniese, G.; Magri, B.; Venturi, D.; Andrade, E. Redactable blockchain—or-rewriting history in bitcoin and friends. In Proceedings of the IEEE European Symposium on Security and Privacy (EuroS\&P), Paris, France, 26-28 April 2017; pp. 111-126.

36. Ross, K. ACWA Power Adopts Blockchain Currency SolarCoin. 2018. Available online: https://www. renewableenergyworld.com/2018/01/18/acwa-power-adopts-blockchain-currency-solarcoin/\#gref (accessed on 1 September 2019).

37. Blockchain: Unchaining Utilities to the Future. Available online: https:/www.arabianindustry.com/utilities/ features/2018/oct/7/blockchain-unchaining-utilities-to-the-future-5987215/ (accessed on 1 September 2019). 
38. Hughes, L.; Dwivedi, K.Y.; Misra, S.K.; Rana, P.N.; Raghavan, V.; Akella, V. Blockchain research, practice and policy: Applications, benefits, limitations, emerging research themes and research agenda. Int. J. Inf. Manag. 2019, 49, 114-129. [CrossRef]

39. Zhao, Y.; Peng, K.; Xu, B.; Liu, Y.; Xiong, W.; Han, Y. Applied engineering programs of energy blockchain in US. In Proceedings of the 10th International Conference on Applied Energy (ICAE2018), Hong Kong, China, 22-25 August 2018. Sci. Direct Energy Procedia 2019, 158, 2787-2793. [CrossRef]

40. Muzammal, M.; Qu, Q.; Nasrulin, B. Renovating blockchain with distributed databases: An open source system. Future Gener. Comput. Syst. 2019, 90, 105-117. [CrossRef]

41. Enescu, F.M.; Bizon, N. SCADA Applications for Electric Power System-Chapter 12. In Reactive Power Control in AC Power Systems; Springer: New York, NY, USA, 2017; pp. 561-609.

42. Enescu, F.M.; Bizon, N.; Moraru, C.M. Issues in Securing Critical Infrastructure Networks for Smart Grid Based on SCADA, Other Industrial Control and Communication Systems: Modeling, Analysis and Practice. In Power Systems Resilience; Springer: New York, NY, USA, 2018.

43. Enescu, F.M.; Marinescu, C.-N.; Ionescu, V.M.; Stirbu, C. System for monitoring and controlling renewable energy sources. In Proceedings of the 2017 9th International Conference on Electronics, Computers and Artificial Intelligence (ECAI), Targoviste, Romania, 29 June-1 July 2017. [CrossRef]

44. Bordel, B.; Martin, D.; Alcarria, R.; ROBLES, T. A Blockchain-based Water Control System for the Automatic Management of Irrigation Communities. In Proceedings of the 2019 IEEE International Conference on Consumer Electronics (ICCE), Las Vegas, NV, USA, 11-13 January 2019; p. 5.

45. Caro, M.P.; Ali, M.S.; Vecchio, M.; Giaffreda, R. Blockchain-based traceability in Agri-Food supply chain management: A practical implementation. In Proceedings of the 2018 Conferince IEEE: IoT Vertical and Topical Summit on Agriculture-Tuscany (IOT Tuscany), Tuscany, Italy, 8-9 May 2018; p. 4.

46. Chilundo, R.J.; Diana Nevesc, D.; Urânio, S.; Mahanjane, U.S. Photovoltaic water pumping systems for horticultural crops irrigation: Advancements and opportunities towards a green energy strategy for Mozambique. Sustain. Energy Technol. Assess. 2019, 33, 61-68. [CrossRef]

47. Casa pepenilor. Available online: https://www.dor.ro/casa-pepenilor/ (accessed on 2 December 2019).

48. De ce Aeceta Distruge Agricultura Romaniei. Un Raport Parlamentar Dezvaluie Delapidarea Sistemului de Irigatii. Available online: https://www.ancheteonline.ro/2012/08/de-ce-seceta-distruge-agricultura-romanieiun-raport-parlamentar-dezvaluie-delapidarea-sistemului-de-irigatii/ (accessed on 2 December 2019).

49. Ahl, A.; Yarime, M.; Tanaka, K.; Tanaka, K.; Sagawa, D. Review of blockchain-based distributed energy: Implications for institutional development. Renew. Sustain. Energy Rev. 2019, 107, 200-211. [CrossRef]

50. Bousfield, D. Crypto-coin hierarchies: Social contestation in blockchain networks. Artic. Glob. Netw. May 2019, 19, 291-307. [CrossRef]

51. Andoni, M.; Robu, V.; David Flynn, D.; Abram, S.; Geach, D.; Jenkins, D.; McCallum, P.; Peacock, A. Blockchain technology in the energy sector: A systematic review of challenges and opportunities. Renew. Sustain. Energy Rev. 2019, 100, 143-174. [CrossRef]

52. Tan, S.; Wang, X.; Jiang, C. Privacy-Preserving Energy Scheduling for ESCOs Based on Energy Blockchain Network. Energies 2019, 12, 1530. [CrossRef]

53. Brilliantova, V. Blockchain and the future of energy. Technol. Soc. 2019, 57, 39-45. [CrossRef]

54. Zhong, L.; Wu, Q.; Xie, J.; Li, J.; Qin, B. A secure versatile light payment system based on blockchain. Future Gener. Comput. Syst. 2019, 93, 327-337. [CrossRef]

55. Kumar, N.M. Blockchain: Enabling wide range of services in distributed energy system. BeniSuef Univ. J. Basic Appl. Sci. 2018, 7, 701-704. [CrossRef]

56. Khaqqi, K.N.; Sikorski, J.J.; Hadinoto, K.; Kraft, M. Incorporating seller/buyer reputation-based system in blockchain-enabled emission trading application. Appl. Energy 2018, 209, 8-19. [CrossRef]

57. Rathore, S.; Pan, Y.; Park, J.H. BlockDeepNet: A Blockchain-Based Secure Deep Learning for IoT Network. Sustainability 2019, 11, 3974. [CrossRef]

58. SolarCoin: A Blockchain-Based Solar Energy Incentive. 2018. Available online: https://solarcoin.org/wpcontent/uploads/SolarCoin_Policy_Paper_EN-1.pdf (accessed on 1 September 2019).

59. Produce One Megawatt Hour. Get One Free SolarCoin. Available online: https://solarcoin.org (accessed on 1 September 2019). 
60. SolarCoin Monetary Policy Proposal to Accelerate the Renewable Energy Transition. Available online: https://medium.com/solarcoin/solarcoin-monetary-policy-proposal-to-accelerate-the-renewableenergy-transition-f46b5d6e7f19 (accessed on 1 September 2019).

61. Yang, L. The blockchain: State-of-the-art and research challenges. J. Ind. Inf. Integr. 2019. [CrossRef]

62. Birleanu, F.G.; Anghelescu, P.; Bizon, N. Malicious and Deliberate Attacks and Power System Resiliency. In Power Systems Resilience; Springer: New York, NY, USA, 2018; pp. 223-246.

63. Huh, S.; Cho, S.; Kim, S. Managing IoT devices using Blockchain platform. In Proceedings of the 2017 19th International Conference on Advanced Communication Technology (ICACT), Pyeongchang, Korea, 19-22 February 2017; pp. 464-467.

64. Zappia, F.; Chen, L.; Pavone, P.; Pisani, R. A Model of Interaction between the Financial Sector and the Energy Sector: The Hypothesis of Energy Currency. Chin. Bus. Rev. 2018, 17, 532-534.

65. T'Serclaes, P. Blockchain Could Be the Missing Link in the Renewable Energy Revolution. World Economic Forum. 21 September 2017. Available online: https://www.weforum.org/agenda/2017/09/blockchainenergyefficiency-finance/ (accessed on 1 September 2019).

66. Andrillon, F. SolarCoin: Incentivising Solar PV Energy Production through Blockchain Innovation. Available online: https://www.pv-tech.org/guest-blog/solarcoin-incentivising-solar-pv-energy-production-throughblockchain-innov (accessed on 1 September 2019).

67. Cryptocurrencies, Blockchain and Pollution. Available online: http://ecoprofit.ro/criptomonedele-blockchainul-si-poluarea/ (accessed on 1 September 2019).

68. Could SolarCoin Help ACWA Boost Its Profits From Solar? Available online: https://www.greentechmedia. com/articles/read/could-solarcoin-help-acwa-boost-its-profits-from-solar (accessed on 1 September 2019).

69. Mihalache, S.F.; Pricop, E.; Fattahi, J. Chap. In Power Systems Resilience; Springer: New York, NY, USA, 2018; pp. 269-287.

70. Casino, F.; Dasaklis, T.K.; Patsakis, C. A systematic literature review of blockchain-based applications:Current status. classification and open issues. Telemat. Inform. 2019, 36, 55-81. [CrossRef]

71. Dinh, T.T.A.; Liu, R.; Zhang, M.; Chen, G.; Ooi, B.C.; Wang, J. Untangling blockchain: A Data Processing View of Blockchain Systems. IEEE Trans. Knowl. Data Eng. 2018, 30, 1366-1385. [CrossRef]

72. Nasrulin, B.; Muzammal, M.; Qu, Q. ChainMOB: Mobility Analytics on Blockchain. In Proceedings of the 19th IEEE International Conference on Mobile Data Management (MDM), Aalborg, Denmark, 25-28 June 2018; pp. 292-293.

73. Wang, X.; Zha, X.; Ni, W.; Liu, R.P.; Guo, J.Y.; Niu, X.; Zheng, K. Survey on blockchain for Internet of Things. Comput. Commun. 2019, 136, 10-29. [CrossRef]

74. Reyna, A.; Martín, C.; Chen, J.; Soler, E.; Díaz, M. On blockchain and its integration with IoT. Challenges and opportunities. Future Gener. Comput. Syst. 2018, 88, 173-190. [CrossRef]

75. Rathorea, P.K.S.; Dasb, S.S.; Chauhana, D.S. Perspectives of solar photovoltaic water pumping for irrigation in India. Energy Strategy Rev. 2018, 22, 385-395. [CrossRef]

76. Ranjbarana, P.; Yousefia, H.; Gharehpetianb, G.B.; Astaraeia, F.R. A review on floating photovoltaic (FPV) power generation units. Renew. Sustain. Energy Rev. 2019, 110, 332-347. [CrossRef]

77. Cazzaniga, R.; Cicu, M.; Rosa-Clot, M.; Rosa-Clot, P.; Tina, G.M.; Ventura, C. Floating photovoltaic plants: Performance analysis and design solutions. Renew. Sustain. Energy Rev. 2018, 81, 1730-1741. [CrossRef]

78. Sahu, A.; Yadav, N.; Sudhakar, K. Floating photovoltaic power plant: A review. Floating photovoltaic plants: Performance analysis and design solutionso. Renew. Sustain. Energy Rev. 2016, 66, 815-824. [CrossRef]

79. Balaj, I.C. Possibilities of Using Solar Energy in Land Improvement Arrangements. Available online: https:/dspace.upt.ro/jspui/bitstream/123456789/353/1/Teza\%20doctorat\%20Balaj\%20Ciprian.pdf (accessed on 2 December 2019).

80. Maican, E. Renewable Energy Systems; Publishing House Printech: Bucureşti, Romania, 2015; ISBN 978-606-23-0359-4. isbn.pub.ro.

81. Campana, P.E.; Wasthage, L.; Nookuea, W.; Tan, Y.; Yan, J. Optimization and assessment of floating and floating-tracking PV systems integrated in on- and off-grid hybrid energy systems. Solar Energy 2019, 177, 782-795. [CrossRef] 
82. Liu, L.; Sun, Q.; Li, H.; Yin, H.; Ren, X.; Wennersten, R. Evaluating the benefits of Integrating Floating Photovoltaic and Pumped Storage Power System. Energy Convers. Manag. 2019, 194, 173-185. [CrossRef]

83. Sahu, A.K.; Sudhakar, K. Effect of UV exposure on bimodal HDPE floats for floating solar application. J. Mater. Res. Technol. 2019, 8, 147-156. [CrossRef] 